\title{
Epidemiologia da doença de Carlos Chagas no Estado do Rio Grande do Sul - Brasil (1)
}

\author{
por \\ César Pinto \\ (Com 26 figuras) \\ INTRODUÇÃO
}

O estudo da epidemiologia da tripanosomiasis cruzi ou doença de Carlos Chagas (Trypanosoma cruzi Chagas, 1909) deverá ser feito em diferentes regiões fisiográficas (Fig. 1) onde ocorrerem as espécies de Triatomídeos, relacionadas com a infecção dêstes transmissores pelo agente eitológico da doença, com o habitat preferido pelos hemipteros além da infecção natural nos hospedadores primitivos (Dasipodídeos, Didelfídeos etc.); os mamíferos domésticos que convivem juntamente com o homem (cão, gato) desempenham importantíssimo papel epidemiológico, pelo fato de se apresentarem freqüentemente parasitados pelo Trypanosoma cruzi e assim concorrendo para infectar os Triatomídeos que por sua vez transmitem a doença aos moradores dos domicílios que abrigam tais animais.

As pesquisas que realizamos durante três anos em épocas diferentes do ano em diversas regiões fisiográficas do Estado do Rio Grande do Sul (Brasil) vieram demonstrar fatos epidemiológicos inéditos e de grande valor para o conhecimento da patologia e da epidemiologia desta doença, referentes aos hábitos do Triatoma infestans que é encontrado nas casas de alvenaria, proliferando em quantidade incrivel sob os colchões das camas (Fig, 16) das pessoas residentes nesse tipo de casa inteiramente diferente do rancho de barro ou de pau a pique em cujas frestas os insetos se abrigam e procriam.

Demonstramos também que os Triatomídeos observados no Rio Grande do Sul (Triatoma infestans, E. rubrovaria, P. megistus etc.) resistem e proliferam em temperaturas abaixo de zero grau centígrado (Figs. 7-11), permanecendo infectados pelo Trypanosoma cruzi, o que foi verificado experi-

(1) Trabalho do Departamento Estadual de Saúde do Rio Grande do Sul, sob a direção do Dr. C. F. Buys e do Instituto Ostvaldo Cruz do Rio de Janeiro. 
mentalmente inoculando-se fezes de Triatoma infestans em ratão do banhado ou nútria: Myocastor coypus.

O estudo de 73 casos humanos de doença de Carlos Chagas, dos quais 27 inéditos, também demonstrou fatos importantes não só referentes à incidência da referida tripanosomiasis nas populações do interior que em certos municípios do Rio Grande do Sul entrevendo a relação de causa e efeito entre a picada do Triatoma infestans e o aparecimento do sinal de Romaña \& Mazza, chamam na picada de chupão.

Antes de referirmos os fatos epidemiológicos de maior importância observados na doença de Carlos Chagas no Rio Grande do Sul, daremos um resumo das regióes fisiográficas e do clima daquele Estado onde no inverno a temperatura cai comumente a zero ou abaixo de zero (Fig. 11), com geadas e nevadas (Fig. 7-10) em quase todos os municipios.

\section{Aspectos fisiográficos do Rio G. do Sul}

(Fig. 1)

As posições geográficas dos pontos extremos do Estado do Rio Grande do Sul (Brasil), são as seguintes, segundo J. A. L. Tupy Caldas (1942):

\begin{tabular}{|c|c|c|c|}
\hline LADOS & PONTOS EXTREMOS & LATITUDE & $\begin{array}{l}\text { LONGITUDE } \\
\text { W. GR. }\end{array}$ \\
\hline $\begin{array}{l}\text { Norte. } \\
\text { Sul.... } \\
\text { Leste.. } \\
\text { Oeste. . }\end{array}$ & 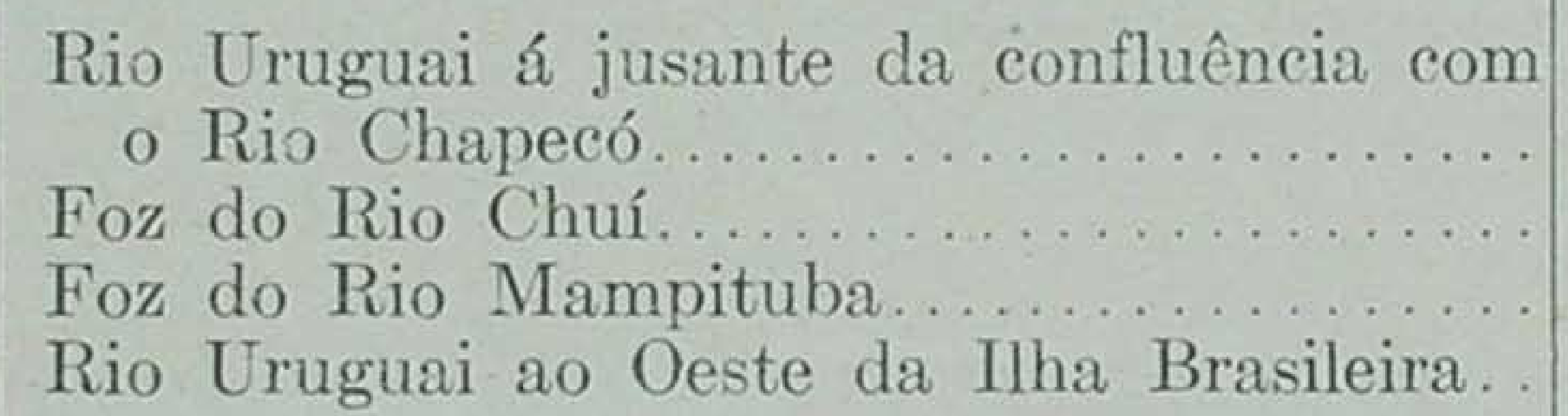 & $\begin{array}{l}27^{\circ} 05^{\prime} 22^{\prime \prime} \\
33^{\circ} 46^{\prime} 06^{\prime \prime} \\
29^{\circ} 19^{\prime} 22^{\prime \prime} \\
30^{\circ} 11^{\prime} 03^{\prime \prime}\end{array}$ & $\begin{array}{l}53^{\circ} 03^{\prime} 24^{\prime \prime} \\
53^{\circ} 25^{\prime} 21^{\prime \prime} \\
49^{\circ} 42^{\prime} 41^{\prime \prime} \\
57^{\circ} 39^{\prime} 07^{\prime \prime}\end{array}$ \\
\hline
\end{tabular}

Essas posições geográficas delimitam uma área de 285.500 quilômetros quadrados (Barão Homem de Melo), ou 285.289, segundo o Instituto Nacional de Estatística.

Os limites do Estado do Rio Grande do Sul são: ao Norte, com o Estado de Santa Catarina; a Leste, com o Oceano Atlântico; ao Sul, com a República do Uruguai; a Oeste, com as Repúblicas do Uruguai e Argentina.

A linha divisória de maior extensão é a do Norte com 958 quilômetros. A linha divisória com a República do Uruguai tem 856 quilômetros. A linha divisória com a República Argentina tem 674 quilômetros.

A extensão da Costa do Oceano Atlântico é de 622 quilômetros.

O perimetro do Estado do Rio Grande do Sul abrange 3110 quilômetros.

Os pontos extremos do Norte ao Sul do Estado distam 740 quilômetros, ao passo que de Leste a Oeste medem 768 quilômetros, dando um contôrno que se aproxima de um losango, podendo ser comparado a um rombóide. 
O Rio Grande do Sul está situado na Zona Temperada, austral, com paisagens de aspecto muito diferentes: floresta tropical (Fig. 2), montanhas elevando se a cêrca de 1.000 metros de altitude (Fig. 3), campos recortados de rios (Fig. 4 e 5); lagoas, algumas delas de grande extensão, situadas nas proximidades do Oceano Atlântico (Fig. 6).

Da área de 285.289 quilômetros quadrados, os campos abertos têm 196. 157 quilômetros quadrados e as florestas abrangem 89.132 quilômetros quadrados. A área lacustre é de 13.110 quilômetros quadrados.

O solo é umedecido por chuvas mais ou menos continuas ao Nordeste, nevadas (Figs. 7, 8, 9 e 10) na região do planalto e geadas em quase todo o território.

As chuvas são maiores no período de Março a Setembro, compreendendo todo o outono, inverno e princípios da primavera.

O clima é temperado, participando das caraterísticas dos tipos superúmido do litoral e semi-úmido continental, com modalidades regionais segundo a altitude, a latitude, a longitude, os ventos, a umidade, as chuvas e as estações do ano.

As oscilações anuais das médias mensais de temperaturas no Rio Grande do $\mathrm{Sul}$ variam entre $9 .^{\circ}, 5 \mathrm{C}$, e e $12 .^{\circ}, 3 \mathrm{C}$.

No Esquema meteorológico do Estado transcrito do trabalho de J. A. L. Tupy Caldas (1942) vêm-se as informações referentes à Meteorologia em cinco cidades: Caxias, Uruguaiana, Santa Maria, Pôrto-Alegre e Santa Vitória do Palmar. (Fig. 11).

ESQUEMA METEOROLÓGICO DO ESTADO DO RIO G. DO SUL. BRASIL

FIG. 11

Latitude Austral,

Longitude W. Gr

Altitude sôbre o nìvel do mar em metros.

Temperatura sensível (centígrado)..

Temperatura média (centígrado)...

Temperatura média das máximas (Co).

Temperatura média das mínimas $(\mathrm{C}, \mathrm{o})$.

Temperatura máxima absoluta (C.o).

Temperatura mínima absoluta $\left(\mathrm{C} . \mathrm{o}^{\circ}\right)$.

Humidade relativa (\%).

Chuvas (quantidade de) $\mathrm{mm}$.

Dias de chuvas (número de)

Dias claros (número de)

Dias encobertos (número de).

Ventos dominantes.

Pressão barométrica $(\mathrm{mm})$
CIDADES COM ESTAÇÕES METEOROLÓGICAS

\begin{tabular}{|c|c|c|c|c|}
\hline $\begin{array}{l}\text { CAXIAS } \\
\text { 8.a Região } \\
\text { Encosta da } \\
\text { Serra }\end{array}$ & $\begin{array}{c}\text { URUGUAIANA } \\
6{ }^{\mathrm{a}} \text { Região } \\
\text { Campanha }\end{array}$ & $\begin{array}{c}\text { SANTA MARIA } \\
7 \text { a Região }^{\text {Depra }} \\
\text { Depresão Cen- } \\
\text { tral }\end{array}$ & $\begin{array}{c}\text { P. ALEGRR } \\
7 \text {. }^{\mathrm{a}} \text { Região } \\
\text { Depressão Cen- } \\
\text { tral }\end{array}$ & $\begin{array}{c}\text { SANTA VITÓRIA } \\
\text { 4a Região } \\
\text { Litoral }\end{array}$ \\
\hline $\begin{array}{c}29^{\circ} 10^{\prime} \\
51^{\circ} 12^{\prime} \\
760 \\
14^{\circ} \\
15^{\circ}, 9 \\
22^{\circ}, 8 \\
11^{\circ}, 5 \\
34^{\circ} \\
-66^{\circ}, 8 \\
82,4 \\
1.983 \\
137 \\
96 \\
124 \\
\text { N. W, }-\mathrm{S}, \mathrm{E} . \\
697\end{array}$ & $\begin{array}{c}29 \circ 45^{\prime} \\
57^{\circ} 01^{\prime} \\
76 \\
16^{\circ}, 8 \\
19^{\circ}, 9 \\
25^{\circ} 8 \\
14^{\circ}, 3 \\
42^{\circ} \\
0^{\circ} \\
73,9 \\
1.351 \\
90 \\
131 \\
94 \\
\text { S. }-\mathrm{E},-\mathrm{E} . \\
755,8\end{array}$ & $\begin{array}{c}29^{\circ} 45^{\prime} \\
53^{\circ} 48^{\prime} \\
139 \\
16^{\circ}, 9 \\
19^{\circ}, 5 \\
26^{\circ}, 1 \\
13^{\circ}, 4 \\
41^{\circ}, 2 \\
-2^{\circ}, 4 \\
77,9 \\
1.807 \\
113 \\
97 \\
92 \\
\text { S. }-\mathrm{E} . \\
749,8\end{array}$ & $\begin{array}{c}30^{\circ} 01^{\prime} \\
51^{\circ} 10^{\prime} \\
15 \\
16^{\circ}, 7 \\
19^{\circ}, 1 \\
24^{\circ}, 5 \\
14^{\circ}, 2 \\
39^{\circ}, 6 \\
-1^{\circ}, 5 \\
74,9 \\
1.299 \\
110 \\
84 \\
105 \\
\text { S. }-\mathrm{E} . \\
760,8\end{array}$ & $\begin{array}{c}33^{\circ} 31^{\prime} \\
53^{\circ} 21^{\prime} \\
7 \\
14^{\circ}, 7 \\
16^{\circ}, 4 \\
21^{\circ}, 6 \\
12^{\circ} \\
28^{\circ}, 3 \\
-5^{\circ}, 2 \\
83,1 \\
1.266 \\
95 \\
106 \\
121 \\
\text { N. E. S. W. } \\
\text { S. W. } \\
760,8\end{array}$ \\
\hline
\end{tabular}


Os ventos dominantes são os de $\mathrm{S} E$ chamados minuano que é frio e úmido, o pampeiro, de $\mathrm{S} \mathrm{W}$, muito mais frio e impetuoso.

\section{Temperaturas no inverno de 1946}

O Instituto Coussirat Araujo, do Serviço de Meteorologia, em Pôrto Alegre, publicou nos jornais diários os dados referentes às temperaturas observadas em diversas cidades do Rio Grande do Sul, que transcrevemos abaixo.

Em 1946 o frio tem sido intenso no Estado do Rio Grande do sul, principalmente entre os dias 15 a 18 de julho, resultante como acontece geralmente da invasão de uma grande massa de ar polar continental.

Em Pôrto Alegre, no dia 18 de julho de 1946, a temperatura mínima acima de $0^{\circ} \mathrm{C}$ foi de $1^{\circ}, 4 \mathrm{C}$., a máxima mais baixa foi de $9^{\circ}, 5 \mathrm{C}$.

Temperaturas acima de $0^{\circ} \mathrm{C}$ em diversas cidades do Rio Grande do Sul, entre 15 a 18 de julho de 1946.

\section{1. ${ }^{a}$ Região Missões Fig. 1}

Santo Angelo

$8^{\circ} \mathrm{C}$.

2. Região Planalto Médio

Júlio de Castilhos

$5^{\circ}, 8 \mathrm{C}$

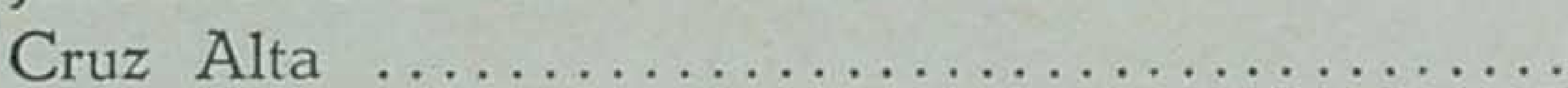

Soledade . . . . . . . . . . . . . . . . . . .

Passo Fundo

$6^{\circ}, 8 \mathrm{C}$

$6^{\circ} \mathrm{C}$.

$6^{\circ}, 6 \mathrm{C}$.

\section{3. ${ }^{n}$ Região Planaldo do Nordeste}

Vacaria . . . . . .....................

$5^{\circ}, 2 \mathrm{C}$.

São Francisco de Paulo .................. $5^{\circ}, 8 \mathrm{C}$.

Lagoa Vermelha ......................

5. ${ }^{a}$ Região Sorta do Sudeste

Piratini . . . . . . . . . . . . . . . . . . . .

Jaguarão . . . . . . . . . . . . . . . . . .

Pelotas . . . . . . . . . . . . . . . . . . . . . . .

\section{6. ${ }^{a}$ Região Campanha}

Alegrete . . . . . . . . . . . . . . . . . . . .

$8^{\circ}, 5 \mathrm{C}$.

Bagé . . . . . . . . . . . . . . . . . . .

$6^{\circ} \mathrm{C}$.

São Gabriel ........................ $7^{\circ}, 6 \mathrm{C}$.

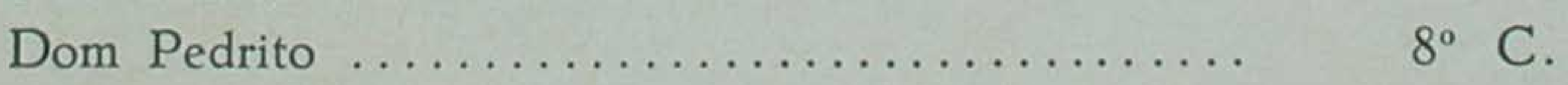

Livramento . . . . . . . . . . . . 


\section{7. ${ }^{a}$ Região Depressão Central}

Santa Maria

$7^{\circ}, 7 \mathrm{C}$.

Cachoeira do Sul

$8^{\circ}, 4 \mathrm{C}$.

8. ${ }^{a}$ Região Encbsta da Serra

Caxias do Sul $4^{\circ}, 6 \mathrm{C}$.

Bento Gonçalves

$5^{\circ} \mathrm{C}$.

Guaporé

$8^{\circ}, 5 \mathrm{C}$.

Taquarí

$8^{\circ}, 6 \mathrm{C}$.

Temperaturas minimas abaixo de $0^{\circ}$ C., observadas no Estado do Rio Grande do Sul, entre 15 e 18 de julho de 1946.

\section{1. ${ }^{a}$ Região Misłsões Fig. 1}

Iraí

$-0^{\circ} \mathrm{C}$.

Santa Rosa

$-2^{\circ} \mathrm{C}$.

Santo Ångelo

$-0^{\circ}, 5 \mathrm{C}$.

Itaqui

$-0^{\circ} \mathrm{C}$.

\section{2." Região Planalto Médio}

Soledade

$-2^{\circ}, 4 \mathrm{C}$.

Cruz Alta

$-1^{\circ}, 2 \mathrm{C}$.

Passo Fundo

$-1^{\circ}, 5 \mathrm{C}$.

Júlio de Castilhos

$-1^{\circ} \mathrm{C}$.

\section{3. ${ }^{\mathrm{R}}$ Região Planaldo do Nordeste}

Lagoa Vermelha

Vacaria

Aparados da Serra

5. ${ }^{a}$ Região Serra do Sudeste

Jaguarão

Pelotas

Piratini

\section{Região Campanha}

Bagé .

Dom Pedrito

Alegrete.

\section{7. ${ }^{a}$ Região Depressão Central}

Cachoeira do Sul

\section{8. ${ }^{a}$ Região Encosta da Serra}

Guaporé

Caxias do Sul

$-1^{\circ}, 8 \mathrm{C}$.

Bento Gonçalves

Taquari $-3^{\circ}, 1 \mathrm{C}$.

$-4^{\circ}, 4 \mathrm{C}$.

$-6^{\circ} \mathrm{C}$. $-0^{\circ} \mathrm{C}$.

$-0^{\circ} \mathrm{C}$.

$-1^{\circ} \mathrm{C}$.

$-0^{\circ}, 5 \mathrm{C}$.

$-0^{\circ} \mathrm{C}$. $-1^{\circ}, 4 \mathrm{C}$.

$-0^{\circ}, 5 \mathrm{C}$.

$-0^{\circ}, 2 \mathrm{C}$. 
De tôdas as regiões fisiográficas do Estado do Rio Grande do Sul, a unica que não apresenta Triatomídeos até, a presente data, é a do Litoral, (Fig. 6) abrangendo a faixa à beira do Oceano Atlântico, embora em municípios próximos do mar (Santo Antônio e Pelotas) aquêles insetos tenham sido observados.

Os Triatomídeos resistem muito bem às temperaturas mais baixas registradas em diversas regióes fisiográficas do Estado do Rio Grande do Sul, como aliás é observado em outros paises de clima temperado, como, por exemplo, o Uruguai, Argentina etc.

\section{Influência da temperatura baixa sôbre os Triatomideos infectados}

Em 1942 verificamos que o Triatoma infestans no municipio de Uruguaiana é encontrado vivo e infectado pelo Trypanosoma cruzi em rancho destruido há mais de dois meses, o que foi demonstrado pela inoculação experimental de fezes daquele barbeiro em Myocastor coypus (ratão do banhado ou nútria) por C. Pinto \& Alcebiades Rolim. Os exemplares de T. infestans naquela região (Ipané, município de Uruguaiana) resistem à temperatura de $0^{\circ}$ centígrado nos meses de julho e agôsto, os mais frios do inverno e apesar disso apresentavam-se infectados intensamente pelo Trypanosoma cruzi. Este fato tem extraordinária importância na epidemiologia da doença de Carlos Chagas e difere inteiramente do que se observa na malária onde abaixo de 15 graus centigrados os Plasmodeos não evolvem nas Anofelinas transmissoras.

O Dr. Clóvis Itaqui Trindade, eminente colega, chefe do Pôsto de Higiene de Encruzilhada do Sul, no Estado do Rio Grande do Sul, fazendo estudos sôbre a doença de Carlos Chagas naquele município, baseando se na freqüência do sinal de Romanã e Mazza nas crianças residentes no interior, informa que

é tão comum, em certas zonas, aquêle quadro clínico, que os "leigos, entrevendo a relação de causa e efeito, chaman'no de "picjada de chupão.

Em 1941 demonstramos que nos municípios do Estado do Rio Grande do Sul infestados por duas espécies de Triatomídeos, uma doméstica (Triatoma infestans) e outra semi-doméstica (Eutriatoma rubrovaria), sòmente a primeira ( $T$. infestans) é encontrada nos ranchos, nas casas de madeira e nos galinheiros sugando o sangue respectivamente do homem e das aves c'omésticas. 
Nas casas de madeira os exemplares de Triatoma infestans apresentavamse infectados pelo Trypanosoma cruzi em cêrca de $90 \%$, ao passo que os Triatomídeos daquela espécie que vivem nos galinheiros jamais apresentam nas fezes, as formas evolutivas do agente etiológico da doença de Carlos Chagas.

Êste fato de grande importância na epidemiologia desta doença foi observado por nós nos municípios de São Borja e Uruguaiana. Nesta última cidade por exemplo, quase todos os galinheiros das ruas mais centrais são infestados pelo Triatoma infestans que jamais se apresenta parasitado pelo Trypanosoma cruzi.

Também em 1941 observamos no municipio de São Borja a presença do Triatoma infestans em quantidade impressionante procreando sob os colchões das casas de alvenaria onde não havia frestas para o inseto abrigar-se. Os ovos dêste hemiptero em quantidade incrivel eram observados nas tábuas, sob os colchões e no assoalho onde delimitavam nitidamente uma área correspon dente à da cama dos habitantes da casa. Êste curioso hábito daquele barbeiro foi verificado por nós, e pela Dra. Maria Clara Mariano da Rocha numa estância do município de São Borja e naturalmente deverá ser freqüente e deve ser pesquisado pelos autores em tôdas as regiões infestadas pelos Triatomideos. Esta verificação demonstra que mesmo nas casas de alvenaria pode instalar-se o Triatoma infestans que se reproduz e é encontrado em tôdas as fases evolutivas sob os colchões dos domicílios, hábito próprio dos percevejos Cimicídeos que vivem nas camas do homem (Cimex hemipterus e Cimex lectularius).

No mapa (Fig. 12) damos as porcentagens de infecção dos Triatomídeos pelo Trypanosoma cruzi nos municipios do Estado do Rio Grande do Sul onde foram feitas pesquisas parasitológicas com fins epidemiológicos. Por êsses dados verifica-se a altíssima infecção daqueles transmissores em zonas rurais onde no inverno a temperatura cai a $0^{\circ} \mathrm{C}$. Êsses dados também demonstram mais uma vez a gravidade dêste grande problema de saúde pública que já deveria ter merecido melhor atenção por parte das autoridades sanitárias qua assistem de braços cruzados o espetáculo desolador de milhares de indivíduos residentes no interior ou empregados nas estâncias ou fazendas sujeitos contìnuamente a infecção pelo Trypanosoma cruzi, acompanhada pela anemia ocasionada por milhares de Triatomídeos que obrigatòriamente se alimentam do sangue dêsses desamparados sociais.

A presença do Trypanosoma cruzi nos Triatomídeos de um domicilio é igual à infecção do homem ou dos mamiferos domésticos (cão, gato, etc.) que 
vivem numa determinada casa ou rancho qualquer que seja o tipo de habitação: alvenaria, rebocada com barro (rancho ou cafua) ou de madeira. Esste fato é primordial e o mais importante na epidemiologia da tripanosomiasis atuzi ou doença de Carlos Chagas.

\section{Municipios infestados no Rio Grande do Sul (Figs. 13 e 14)}

Em 1942 quando o Estado do Rio Grande do Sul tinha 88 municípios a situação referente aos Triatomídeos e suas relações com os casos de doença de Chagas era a seguinte: (Fig. 13)

\begin{tabular}{|c|c|}
\hline Municipios do Estado, em 1942 & 88 \\
\hline Com Triatomideos em 1942 & 35 ou $39,8 \%$ \\
\hline Com casos humanos até 1942 & 9 ou $10,2 \%$ \\
\hline Com casos em animais até 1942 & 5 ou $5,7 \%$ \\
\hline
\end{tabular}

Em 1946 a situação é a seguinte:

Municipios do Estado em 1946 ............ 92

Com Triatomídeos até $1946 \ldots \ldots \ldots \ldots \ldots .49$ ou $53,2 \%$

Com Triatomídeos infectados pelo

Trypanosoma cruzi até $1946 \ldots \ldots \ldots \ldots .25$ ou $30,4 \%$

Com casos humanos até $1946 \ldots \ldots \ldots \ldots .22$ ou $23,9 \%$

Com casos em animais até $1946 \ldots \ldots \ldots \ldots .6$ ou $6,5 \%$

As porcentagens de infecção natural dos Triatomídeos pelo Trypanosoma cruzi nos municípios do Estado do Rio Grande do Sul, são indicadas no mapa da Fig. 12.

Municipios do Estado do Rio Grande do Sul infestados por Triatomideos (Fig. 14)

Dos 92 municípios que fazem parte do Estado do Rio Grande do Sul, 49 estão infestados por Triatomídeos. Os municípios infestados são os seguintes:

1. Herval

2. Pinheiro Machado

3. Bagẻ

4. Don Pedrito

5. Lavras do Sul

6. São Gabriel

7. Livramento

8. Rosário do Sul

9. Alegrete

10. Quarai

11. Uruguaiana

12. Itaqui
13. São Borja

14. São Luís Gonzaga

15. Santa Rosa

16. Palmeira das Missões

17. Irai

18. Santo Antônio

19. Canoas

20. Pôrto Alegre

21. Tapes

22. Camacuã

23. São Lourenço do Sul

24. Pelotas 
25. Encruzilhada

26. Cachoeira do Sul

27. Canguçu

28. Caçapava

29. São Sepé

30. Rio Pardo

31. São Jerônimo

32. Santa Maria

33. Taquari

34. Triunfo

35. Montenegro

36. Caí

37. São Leopoldo
39. Júlio de Castilhos

39. Cruz Alta

40. Caràzinho

41. Tupanciretã

42. Gel. Vargas

43. São Francisco de Assis

44. Santiago

45. Jaguari

46. Santo Angelo

47. Ijuí

48. Taquara

49. São Francisco de Paula

Casos humanos de doença de Carlos Chagas por municipios do Rio Grande do Sul, de 1939 a 1946

(Fig. 14)

Municipios $\begin{gathered}\mathrm{N} .^{\circ} \text { de } \\ \text { casos } \\ \text { humanos }\end{gathered}$

1. Caçapava ............ 2

2. Cachoeira ............ 1

3. Camacuã ........... 3

4. Canguçu ............. 3

5. Dom Pedrito .......... 2

6. Encruzilhada do Sul ..... 16

7. Herval ............ 1

8. Ijui $\ldots \ldots \ldots \ldots \ldots \ldots, 1$

9. Itaqui . . . . . . . . .

10. Júlio de Castilhos ....... 2

11. Lavras do Sul .......... 1

12. Livramento ........... 1

13. Pelotas . . . . . . . . . . . . 1

14. Rio Pardo $\ldots \ldots \ldots \ldots \ldots$. 1

15. Santa Maria ........... 4

16. Santo Ångelo ........... 25

17. São Jerônimo ........... 3

18. São Luís Gonzaga ...... 1

19. São Sapé $\ldots \ldots \ldots \ldots \ldots \ldots$. 1

20. Sobradinho ........... 1

21. Tupanciretã $\ldots \ldots \ldots \ldots \ldots$. 1

22. Uruguaiana $\ldots \ldots \ldots \ldots \ldots$. 1

Total . . . . . 73 
Número de casos de doença de Carlos Chagas no Estado do Rio Grande do Sul. (Fig. 15)

Desde que foram divulgados amplamente os sinais clínicos mais evidentes na forma aguda da doença, traduzidos principalmente pelo sinal de Romaña \& Mazza, a residencia em ranchos ou em casas infestadas pelo transmissores Triatomídeos, começaram a aparecer as pessoas com casos agudos que procuravam os Postos de Higiene do Departamento Estadual de Saúde instalados em 78 dos 92 municípios que fazem parte do Estado do Rio Grande do Sul.

Os casos agudos e crônicos observados naquele Estado, de 1939 a 1946 são os seguintes.

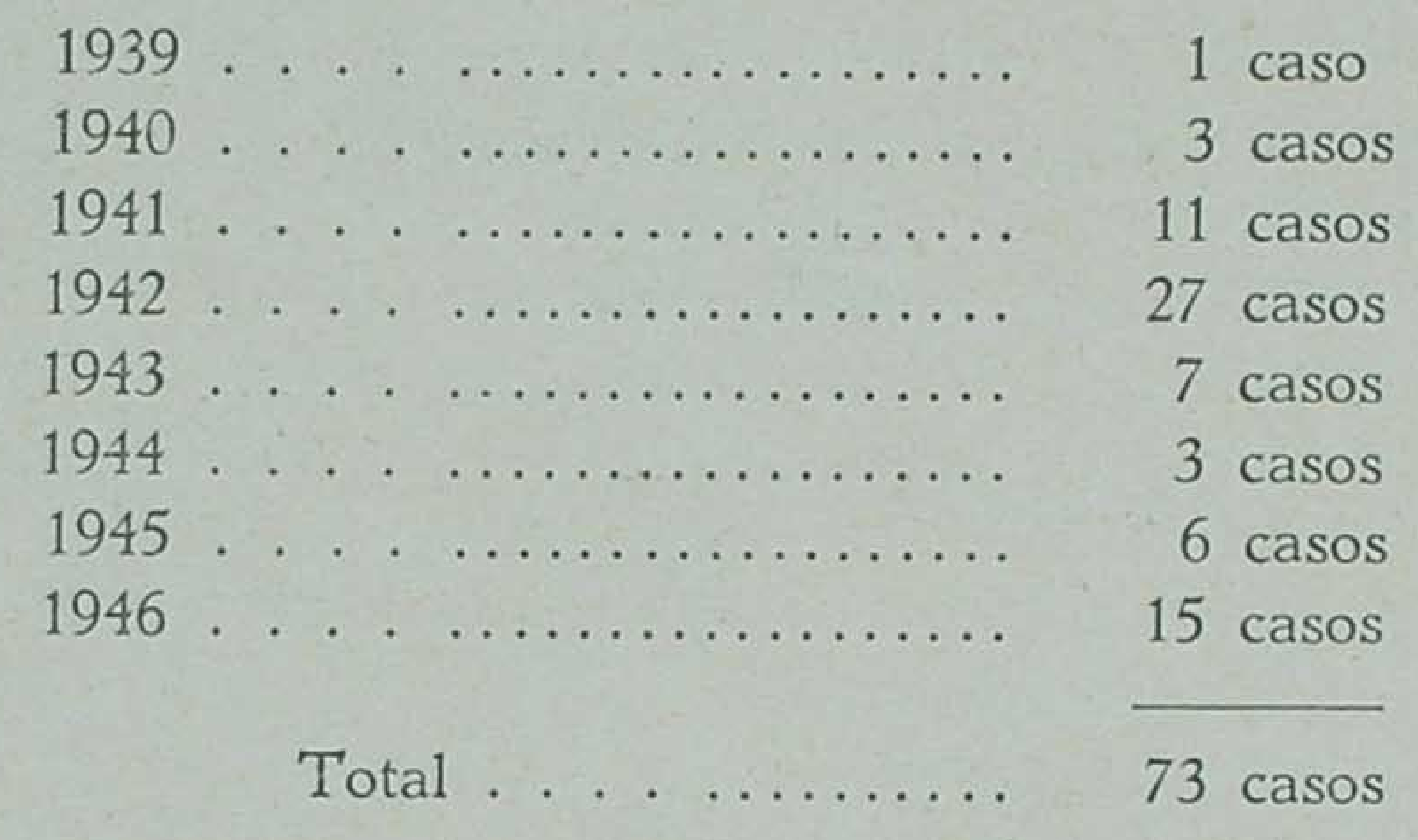

Modo de transmissão do T. cruzi ao homem (Figs. 16 e 17)

O nome vulgar de barbeiro pelo qual os sertanejos de Minas Gerais designam acertadamente os Triatomídeos demonstra a predileção dêstes insetos sugarem as pessoas na face. (Fig. 17)

O acêrto desta observação popular foi confirmado por diversos autores, completada pelas experiências de E. Brumpt, Pirajá da Silva, A. Neiva etc., que demonstraram o exato mecanismo da transmissão do Typanosoma cruzi, feito posteriormente, quando os triatomídeos no momento da picada, emitem ou defecam fezes contendo as formas evolutivas daquele flagelado conhecidas por tripanosomas metacíclicos. (Fig. 17).

Os moradores do interior do município de Encruzilhada do Sul, R. S., dada a freqüência dos Triatomídeos nos domicílios daquela região e o aparecimento do sinal de Romaña \& Mazza nas pessoas que residem em casas infestadas por êstes insetos, chamam a doença de Carlos Chagas pelos nomes sugestivos de picada de chupão, demonstrando assim uma nítida relação de causa e efeito, entre a picada do barbeiro e o aparecimento do edema palpebral. 
Dos 47 casos agudos, referidos neste trabalho, dos quais 27 inéditos, o edema palpebral ou sinal de Romaña \& Mazza foi positivo em $100 \%$. (Fi gura 18).

O aparecimento deste importantíssimo sinal na fase aguda é brusco e in dolor, conforme relatou-nos um doente residente em rancho do município de Uruguaiana, altamente infestado por Triatomideos ( $T$. infestans) dos quais $100 \%$ possuiam Trypanosoma cruzi nas fezes, durante o inverno. O referido paciente, homem de cultura regular, porém, muito inteligente, relatounos que o aparecimento do edema palpebral unilateral apareceu-lhe entre meia noite, quando deitou-se, e às seis horas da manhã ao levantar-se. Nesse momento verificou com surprêsa a impossibilidade de abrir as pálpebras do lado em que fora picado pelo barbeiro ou chupão.

\section{Incidência da doença em adultos e crianças}

(Fig. 19)

Dos 73 casos de doença de Carlos Chagas verificados no Estado do Rio Grande do Sul (Brasil) entre 1939 e 1946, quarenta e sete foram em crianças (Fig. 19), vinte e dois em adultos e quatro ignorados, dando respectivamente as seguintes porcentagens :

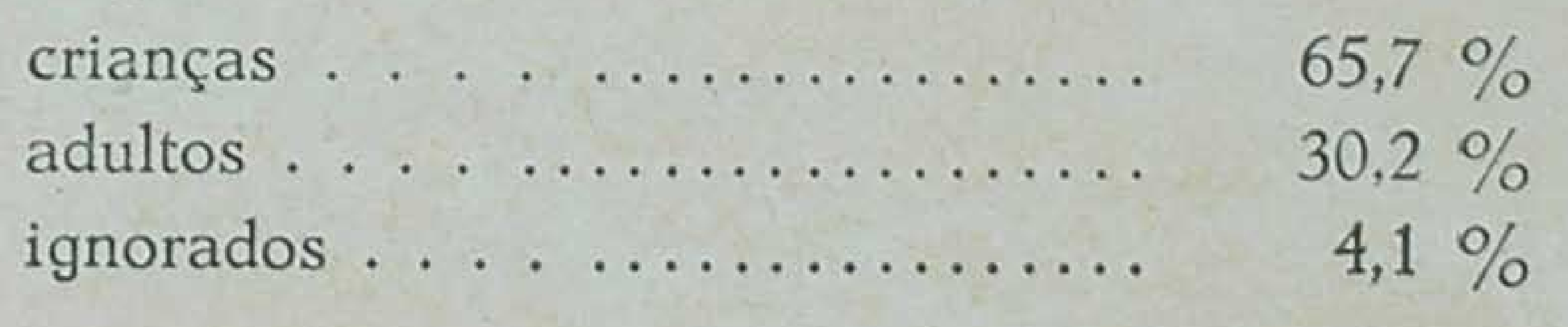

Casos agudos

Fig. 20

Os casos agudos da doença de Carlos Chagas observados entre 1939 e 1946 no Estado do Rio Grande do Sul (Brasil), foram nas seguintes porcentagens :

$$
\begin{aligned}
& \text { Adutos .......... } 7 \text { casos ou } 14,6 \% \\
& \text { Crianças ......... } 38 \text { casos ou } 79,2 \% \\
& \text { Ignorados......... } 2 \text { casos ou } 6,2 \%
\end{aligned}
$$

Casos cronicos em adultos e crianças

Fig. 21

Dos 25 casos crônicos da doença de Carlos Chagas registrados entre 1939 e 1946 foram nas seguintes porcentagens: (Fig. 21).

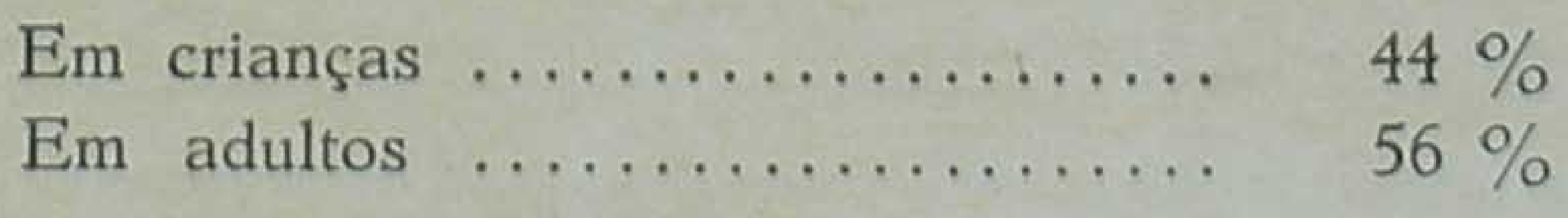


Todos êsses casos foram registrados em domicilios altamente infestados pelo Triatoma infestans com elevadas porcentagens de infecção natural pelo Trypanosoma cruzi nos insetos transmissores tanto no verão como no inverno inclusive nos meses mais frios com temperaturas abaixo de zero.

\section{Incidência da doença por côt}

Fig. 22

No Estado do Rio Grande do Sul (Brasil) os negros e mulatos não são muito numerosos. Tôdas as raças estão sujeitas à infecção pelo Trypanosoma cruzi desde que tenham contato com os transmissores nos domicílios infestados pelos Triatomídeos contendo o agente etiológico no aparelho digestivo.

A inciência por côr foi a seguinte: (Fig. 22)

\begin{tabular}{|c|c|}
\hline Em pessoas de côr branca & 38 casos ou $52,1 \%$ \\
\hline Em pessoas de côr preta & 4 casos ou $5,5 \%$ \\
\hline Em pessoas mulatas & 3 casos ou $4,1 \%$ \\
\hline Ignorados & 28 casos \\
\hline
\end{tabular}

O grande número de ignorados é registrado devido ao fato lamentável de Simões e Tupinambá (1942) não terem referido a côr dos doentes que observaram no Rio Grande do Sul.

\section{Sinal de Romaña \& Mazza}

Fig. 23

Todos os casos agudos referidos neste trabalhos foram devidos ao sinal de Romaña \& Mazza, largamente conhecido pelos médicos chefes dos Postos de Higiene e de grande número de clínicos que exercem a profissão no interior do Estado do Rio Grande do Sul.

O edema palpebral unilateral de uma ou de ambas as pálpebras ou sinal de Romaña \& Mazza (Fig. 17 e 18) quando verificado em pessoa residente em casa infestada por Triatomídeos infectados pelo Trypanosoma cruzi, aparecendo bruscamente e indolor é igual a doença de Carlos Chagas.

Nos 47 casos agudos que referimos aqui o sinal de Romaña \& Mazza foi positivo em $100 \%$. 
Quanto à localização, $72,8 \%$ (Fig. 23) foram unilaterais, 22,7\% foram bilaterais e 4,5\% não informaram em qual das pálpebras havia edema.

Febre nos casos agudos

Fig. 24

$\mathrm{Na}$ fase aguda da doença de Carlos Chagas a febre foi verificada em $49 \%$ dos casos (Fig. 24), não sendo muito elevada, atingindo no máximo $38^{\circ}$ centígrados, aparecendo irregularmente durante poucos dias ou prolongando-se por um mês, de acôrdo com o que foi dado observar ou coligir nos casos referidos neste trabalho.

\section{Pertubações cardiacas na fase aguda}

Fig. 25

Dos 47 casos agudos referidos neste trabalho $27,7 \%$ (Fig. 25) apresentavam perturbações cardiacas traduzidas por deficiência miocárdica, taquicardia, arritmia, extra-sístoles ou raramente, num caso, em criança de 13 anos, havia sinais de miocardite em cliente examinada pelo Dr. Clovis I. Trindade, chefe do Pôsto de Higiene de Encruzilhada do Sul, R. S.

Quase todos êsses doentes apresentaram perturbações na fase aguda entre a primeira e a segunda semana após o aparecimento do sinal de Romaña $E$ Mazza. Êsses fatos demonstram um precoce ataque do Trypanosoma cruzi ao miocárdio, na fase aguda da doença de Carlos Chagas.

\section{Diagnóstico}

Fig. 26

Os diagnósticos foram feitos pelo exame de sangue, sendo $46,6 \%$ pelo xenodiagnóstico, 20,6\% pelo exame direto do sangue, colhido na fase aguda.

O diagnóstico clínico-epidemiológico baseado no sinal de Romaña \& Mazza acompanhado da presença de Triatomídeos infectados pelo Trypanosoma cruzi oriundos de domicílios, é decisivo, pois é igual à doença de Carlos Chagas, de acôrdo com o que temos observado nos estudos epidemiológicos desta tripanosomiases não só no Rio Grande do Sul, como em outras regiões endêmicas do Brasil e de outros paises. 
CASOS HUMANOS DE DOENCA DE CARLOS CHAGAS "TRYPANOSOMA CRUZI" OBSERVADOS NO ESTADO DO RIO GRANDE DO SUL (BRASIL) De 1939 a 1946

os CaSOS INDICADOS PFLo SiNaL (*) Sĩo iNÉditos

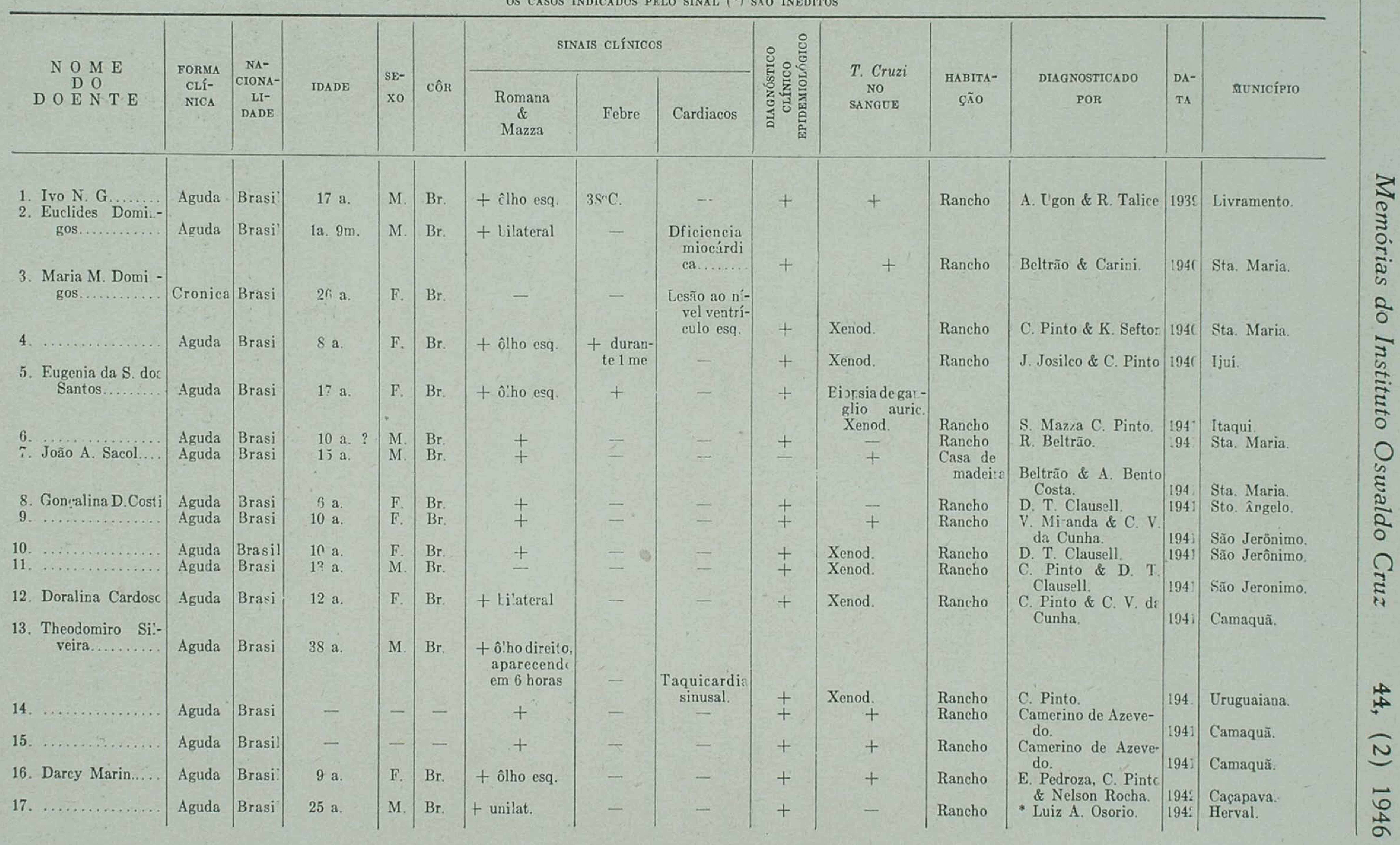




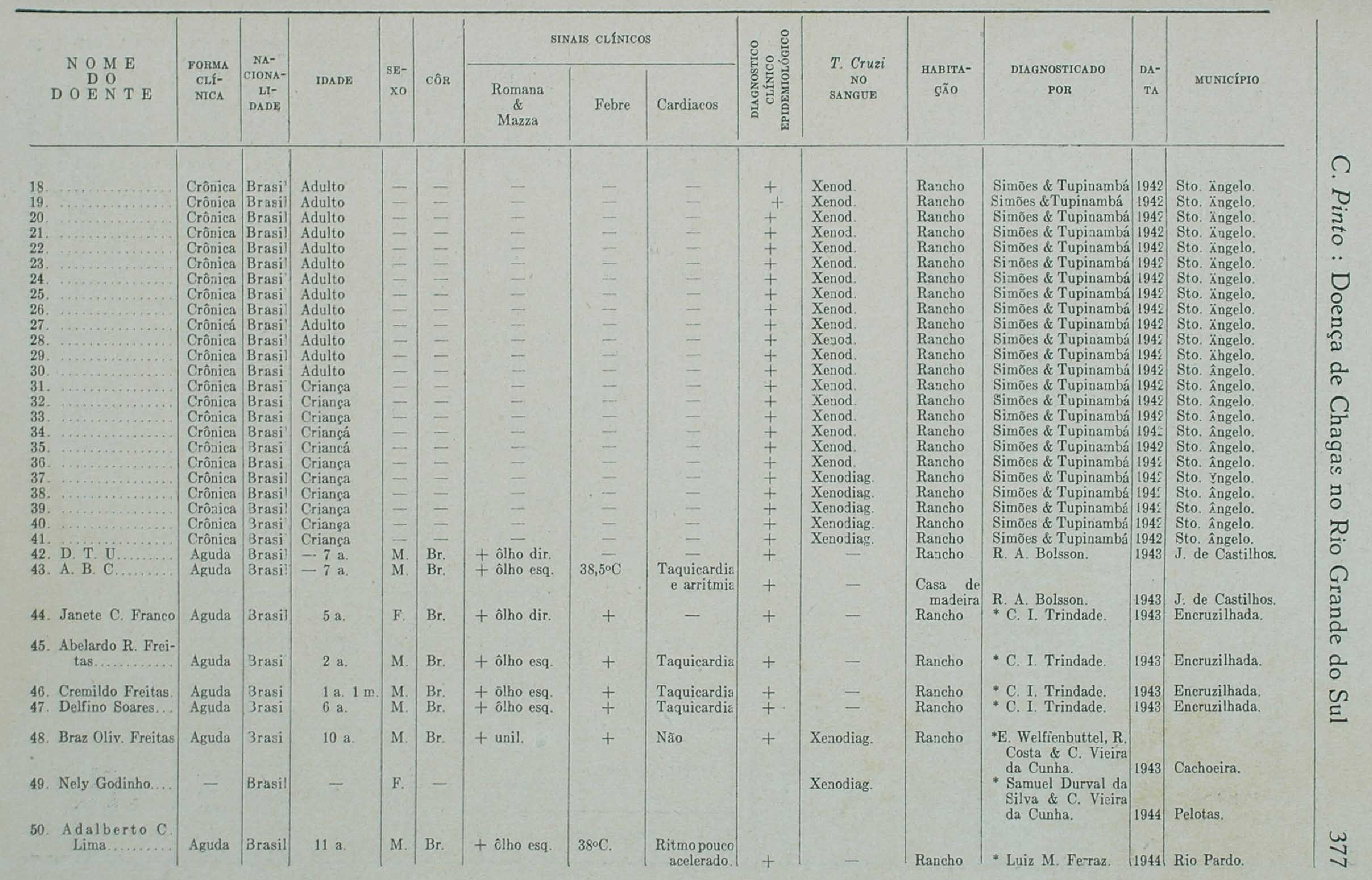




\begin{tabular}{|c|c|c|c|c|c|c|c|c|c|c|c|c|c|c|}
\hline \multirow{2}{*}{$\begin{aligned} & \text { N O M E E } \\
& \text { D O } \\
& \text { D O E N T E }\end{aligned}$} & \multirow{2}{*}{$\begin{array}{l}\text { FORMA } \\
\text { CLI- } \\
\text { NICA }\end{array}$} & \multirow{2}{*}{$\begin{array}{c}\text { NA- } \\
\text { CIONA- } \\
\text { LI- } \\
\text { DADE }\end{array}$} & \multirow{2}{*}{ IDADE } & \multirow{2}{*}{$\begin{array}{c}\text { SE- } \\
\text { xo }\end{array}$} & \multirow{2}{*}{ côR } & \multicolumn{3}{|c|}{ SINAIS CLÍNICOS } & \multirow{2}{*}{ 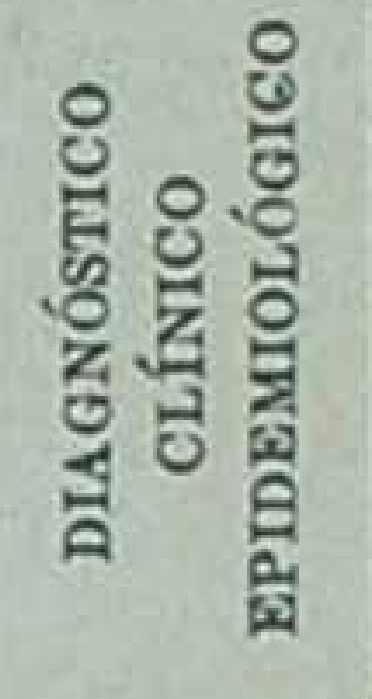 } & \multirow{2}{*}{$\begin{array}{l}\text { T. Cruzi } \\
\text { No } \\
\text { SANGUE }\end{array}$} & \multirow{2}{*}{$\begin{array}{c}\text { HABITA- } \\
\text { C̃̃o }\end{array}$} & \multirow{2}{*}{$\begin{array}{l}\text { DIAGNOSTICADO } \\
\text { POR }\end{array}$} & \multirow{2}{*}{$\begin{array}{c}\mathrm{DA}^{-} \\
\mathrm{TA}\end{array}$} & \multirow{2}{*}{ MUNICÍPIO } \\
\hline & & & & & & $\begin{array}{l}\text { Romana } \\
\& \\
\text { Mazza }\end{array}$ & Febre & Cardíacos & & & & & & \\
\hline 51. Leonor Talorico... & Aguda & Brasil & 9 a. & F. & $\mathrm{Br}$. & + unilat. & + & Não & + & + & - & * Nelson Rocha. & 1944 & Caçapava. \\
\hline 52. & Aguda & Brasil & 42 a. & M. & $\mathrm{Br}$. & + unilat. & + & Sim. & + & + & Rancho. & $\begin{array}{l}\text { * Medici, Teixeira, } \\
\text { Burns, Salis, No- }\end{array}$ & & \\
\hline 53. A. M. & Aguda & Brasil & $13 \mathrm{a}$. & M. & $\mathrm{Br}$. & + ôlho dir. & - & - & + & + & Rancho & E. Dias \& V. Med- & $\begin{array}{l}1940 \\
1945\end{array} \mid$ & $\begin{array}{l}\text { Lavras. } \\
\text { Cangussú. }\end{array}$ \\
\hline 54. E. V. S. & Aguda & Brasil & 3 a. & F. & $\mathrm{Br}$ & + ôlho dir. & - & - & + & + & Rancho & $\begin{array}{l}\text { E. Dias \& V. Med- } \\
\text { vedovski. }\end{array}$ & 1945 & Cangussú. \\
\hline 55. J. L. L. & Aguda & Brasil & 8 a. & M. & $\mathrm{Br}$ & + ôlho dir. & - & - & + & + & Rancho & $\begin{array}{l}\text { C. V. da Cunha \& V. } \\
\text { Medvedovski. }\end{array}$ & 1945 & Cangussú. \\
\hline 57. Mario Nobre... & Aguda & Brasil & $15 \mathrm{a}$ & F & Pret. & + ôlho esq. & $37,8^{\circ} \mathrm{C}$ & $\begin{array}{c}\text { Taquicardia } \\
\text { Extra-sis- } \\
\text { toles. } \\
\text { Taquicardia }\end{array}$ & $\begin{array}{l}+ \\
+\end{array}$ & $\begin{array}{l}+ \\
-\end{array}$ & $\begin{array}{l}\text { Rancho } \\
\text { Rancho }\end{array}$ & $\begin{array}{l}\text { V. Medvedovski \& } \\
\text { C. V. da Cunha. } \\
\text { * Gastão Lopes. }\end{array}$ & $\begin{array}{l}194 t \\
1945\end{array}$ & $\begin{array}{l}\text { Sobradinho. } \\
\text { Encruzilhada. }\end{array}$ \\
\hline 58. Oracildo Pereira.. & Aguda & Brasi: & $16 \mathrm{a}$. & M. & $\begin{array}{l}\mathrm{Br} . \\
\mathrm{Br} .\end{array}$ & $\begin{array}{l}\text { + ôlho dir. } \\
\text { + unilat. }\end{array}$ & $\begin{array}{c}37,8^{\circ} \mathrm{C} \quad \mathrm{a} \\
\text { tarde. } \\
-\end{array}$ & - & $\begin{array}{l}+ \\
+\end{array}$ & $\begin{array}{l}+ \\
+\end{array}$ & $\begin{array}{l}\text { Rancho } \\
\text { Rancho }\end{array}$ & $\begin{array}{l}\text { * L. Furtado \& J، Zeil- } \\
\text { man. } \\
\text { * Lauro Bulcão. }\end{array}$ & $\begin{array}{l}1946 \\
1946\end{array}$ & $\begin{array}{l}\text { S. Luiz Gonzaga. } \\
\text { São Sepé. }\end{array}$ \\
\hline 60. Patrocínio Soares & Aguda & Brasil & $14 \mathrm{a}$. & M. & $\mathrm{Br}$ & + ôlho dir. & + & - & + & - & Rancho & * Gastão Lopes. & 1946 & Encruzilhada \\
\hline $\begin{array}{l}\text { 61. Gloria F. Job da } \\
\text { Rosa.......... } \\
\text { 62. Vilon Gonçalves.. }\end{array}$ & $\begin{array}{l}\text { Aguda } \\
\text { Aguda }\end{array}$ & $\begin{array}{l}\text { Brasil } \\
\text { Brasil }\end{array}$ & $\begin{array}{r}13 \text { a. } \\
5 \text { a. }\end{array}$ & $\begin{array}{l}\mathrm{F} \\
\mathrm{M} .\end{array}$ & $\begin{array}{l}\mathrm{Br} . \\
\mathrm{Br}\end{array}$ & $\begin{array}{l}\text { + ôlho dir. } \\
\text { + esq. }\end{array}$ & $\begin{array}{l}- \\
+\end{array}$ & $\begin{array}{l}\text { Sinaisde mi- } \\
\text { ocardite. }\end{array}$ & + & $\overline{-}$ & $\begin{array}{l}\text { Rancho } \\
\text { Rancho }\end{array}$ & $\begin{array}{l}\text { * C. I. Trindade. } \\
\text { * Miguel Castro. }\end{array}$ & $\begin{array}{l}1946 \\
1946\end{array}$ & $\begin{array}{l}\text { Encruzilhada. } \\
\text { Encruzilhada. }\end{array}$ \\
\hline 63. Gercí da Silva Lo- & Aguda & Brasil & $11 \mathrm{a}$. & F. & Mul. & + & - & - & + & - & Rancho & * Miguel Castro. & 1946 & Encruzilhada. \\
\hline 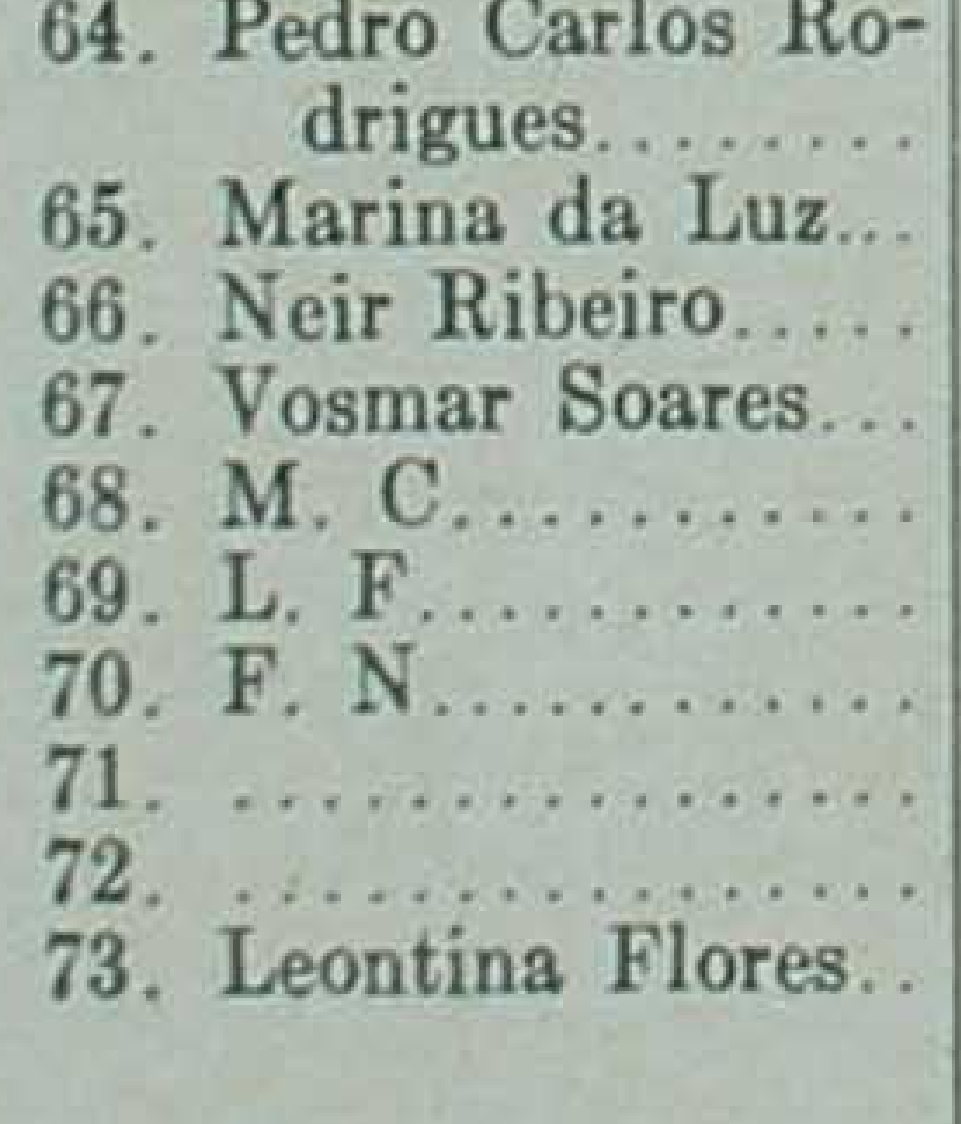 & $\begin{array}{l}\text { Aguda } \\
\text { Aguda } \\
\text { Aguda } \\
\text { Aguda } \\
\text { Aguda } \\
\text { Aguda } \\
\text { Aguda } \\
\text { Aguda } \\
\text { Aguda } \\
\text { Aguda }\end{array}$ & $\begin{array}{l}\text { Brasi! } \\
\text { Brasi } \\
\text { Brasi } \\
\text { Brasil } \\
\text { Brasi! } \\
\text { Brasi } \\
\text { Brasi1 } \\
\text { Brasil } \\
\text { Brasi } \\
\text { Brasil }\end{array}$ & $\begin{array}{rl}6 & \mathrm{a} . \\
26 & \mathrm{a} . \\
3 \mathrm{a} & \\
7 & \mathrm{a} \\
19 & \mathrm{a} . \\
4 & \mathrm{a} . \\
11 \mathrm{a} . \\
4 \mathrm{a} \\
6 \mathrm{a} \\
10 \mathrm{a} .\end{array}$ & $\begin{array}{l}\text { M. } \\
\mathrm{F} \\
\mathrm{F} \\
\mathrm{M} \\
\mathrm{F} \\
\mathrm{M} \\
\mathrm{F} \\
\mathrm{F} \\
\mathrm{F} \\
\mathrm{F}\end{array}$ & $\begin{array}{l}\text { Pret. } \\
\text { Mul. } \\
\text { Br. } \\
\text { Pret. } \\
\text { Br. } \\
\text { Mul. } \\
\text { Br. } \\
\text { Pret. } \\
\text { Br. } \\
\text { Br. }\end{array}$ & $\begin{array}{l}\text { + ôlho dir. } \\
\text { + ôlho dir. } \\
\text { + ôho dir. } \\
\text { + ôlho esq. } \\
\text { + ôlho esq. } \\
\text { + ôlho esq. } \\
\text { + ôlho esq. } \\
\text { + unilat. } \\
\text { + unilat. } \\
\text { + }\end{array}$ & $\begin{array}{l}\frac{+}{+} \\
+ \\
+ \\
+ \\
+ \\
\text { Não } \\
\text { Não } \\
38^{\circ} \mathrm{C}\end{array}$ & 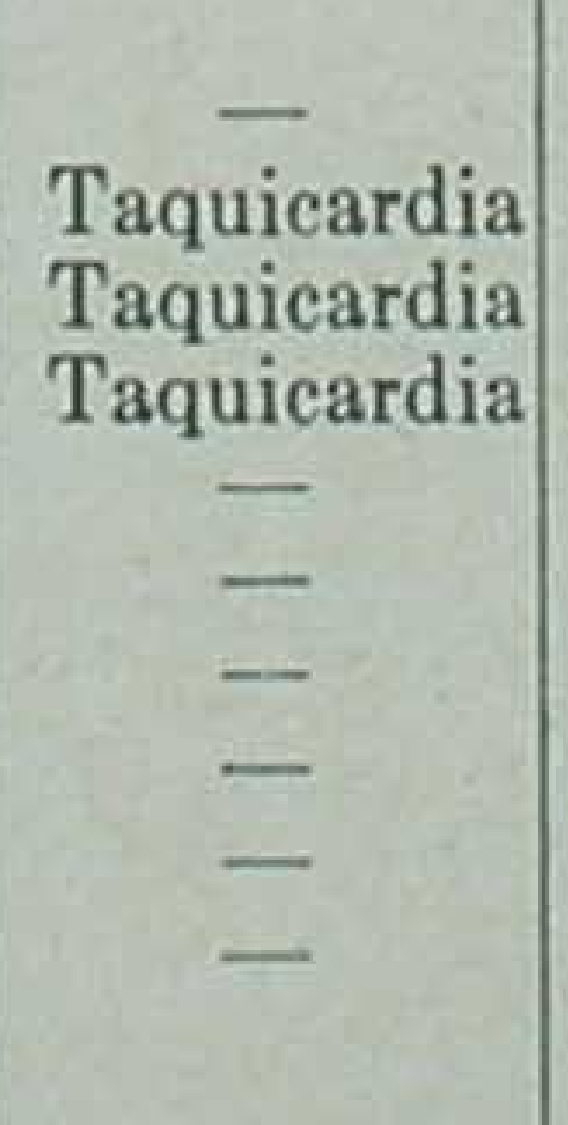 & $\begin{array}{l}+ \\
+ \\
+ \\
+ \\
+ \\
+ \\
+ \\
+ \\
+ \\
+\end{array}$ & $\begin{array}{l}\bar{z} \\
\bar{E} \\
\bar{z} \\
\bar{z} \\
\bar{t}\end{array}$ & $\begin{array}{l}\text { Rancho } \\
\text { Rancho } \\
\text { Rancho } \\
\text { Rancho } \\
\text { Rancho } \\
\text { Rancho } \\
\text { Rancho } \\
\text { Rancho } \\
\text { Rancho } \\
\text { Casa de } \\
\text { madeira }\end{array}$ & $\begin{array}{l}\text { * Joaquim A. Osório } \\
\text { * Gastão Lopes. } \\
\text { * C. I. Trindade. } \\
\text { * C. I. Trindade. } \\
\text { * Jorge Morais. } \\
\text { * Jorge Morais } \\
\text { * Jorge Morais. } \\
\text { * A. Mercio Xavier. } \\
\text { * A. Mercio Xavier. } \\
\text { * Abrão Carpilovski. }\end{array}$ & \begin{tabular}{|l|l|}
1946 \\
1946 \\
1946 \\
1946 \\
1946 \\
1946 \\
1946 \\
1946 \\
1946 \\
1946 \\
\end{tabular} & $\begin{array}{l}\text { Encruzilhada. } \\
\text { Encruzilhada. } \\
\text { Encruzilhada. } \\
\text { Encruzilhada. } \\
\text { Eneruzilhada. } \\
\text { Encruzilhada. } \\
\text { Encruzilhada. } \\
\text { D. Pedrito. } \\
\text { D. Pedrito. } \\
\text { Tupanciretā. }\end{array}$ \\
\hline
\end{tabular}


MAMİFEROS HOSPEDADORES PRIMITIVOS DO TRYPANOSOMA CRUZI OBSERVADOS NO ESTADO DO RIO GRANDE DO SUL. BRASIL.

\begin{tabular}{|c|c|c|c|c|c|}
\hline $\begin{array}{c}\text { HOSPEDADORES PRIMITIVOS } \\
\text { EXAMINADOS }\end{array}$ & $\begin{array}{l}\text { NÚMERO DE } \\
\text { EXEMPLARES } \\
\text { EXAMINADOS }\end{array}$ & $\begin{array}{c}\text { POSITIVOS PARA } \\
T . \text { cruzi } \\
\text { NO SANGUE }\end{array}$ & DATA & MUNICÍPIO & OBSERVA DORES \\
\hline 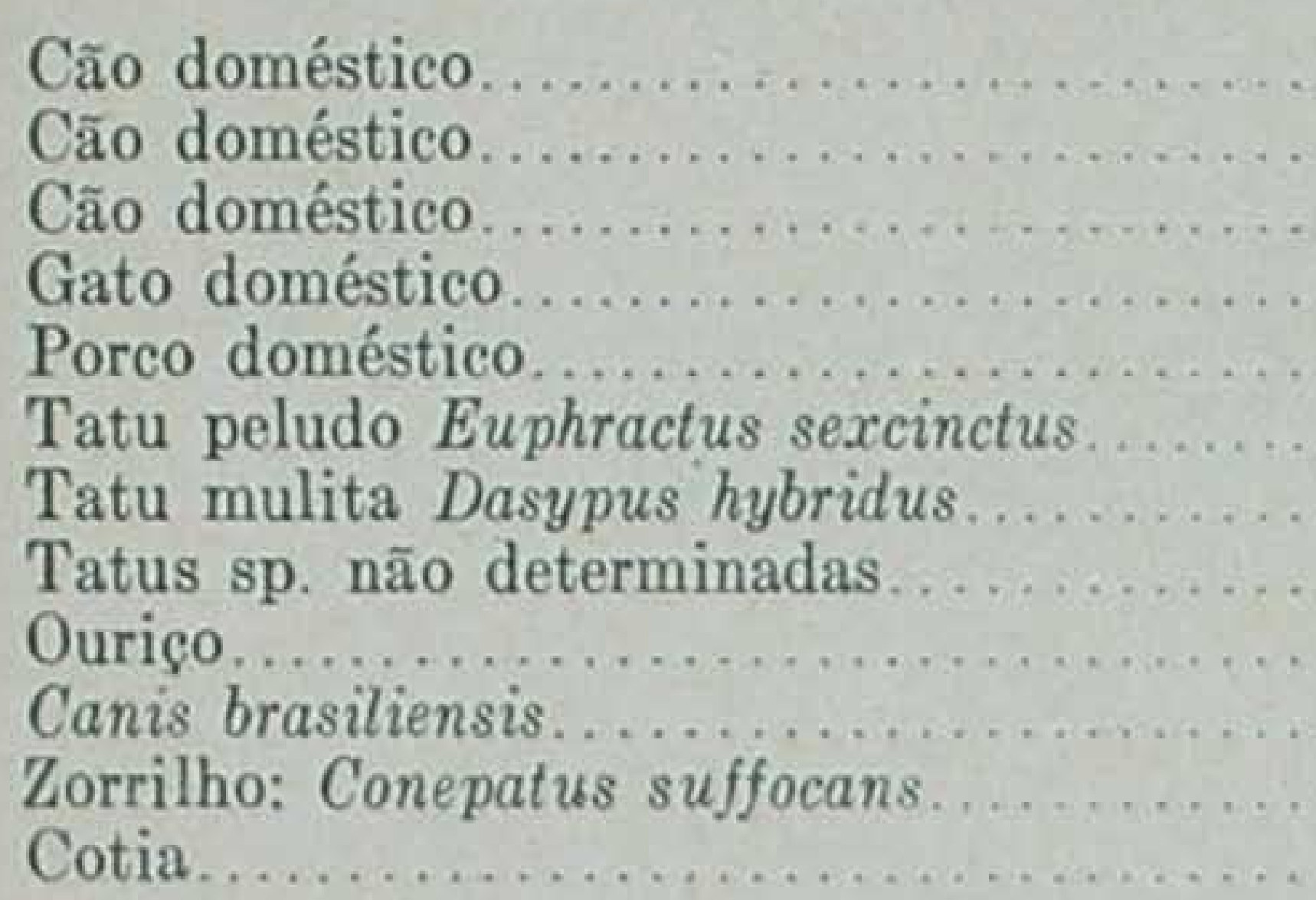 & $\begin{array}{r}1 \\
1 \\
13 \\
7 \\
1 \\
8 \\
\\
10 \\
8 \\
1 \\
1 \\
1\end{array}$ & $\begin{array}{l}1 \\
1 \\
2 \\
0 \\
1 \\
1 \\
1 \\
0 \\
0 \\
0 \\
0 \\
0\end{array}$ & $\begin{array}{l}1940 \\
1941 \\
1942 \\
1942 \\
1941 \\
1941 \\
1942 \\
1942 \\
1942 \\
1942 \\
1942 \\
1942\end{array}$ & $\begin{array}{l}\text { Sta. Maria } \\
\text { S. Jerônimo } \\
\text { Sto. Ângelo } \\
\text { Sto. Angelo } \\
\text { Camaquã. } \\
\text { Uruguaiana } \\
\text { Sto. Ângelo } \\
\text { Sto. Ângelo } \\
\text { Sto. Ângelo } \\
\text { Sto. Ângelo } \\
\text { Sto. Ângelo } \\
\text { Sto. Ângelo }\end{array}$ & $\begin{array}{l}\text { C. Pinto \& K. Sefton } \\
\text { D. T. Clausell. } \\
\text { Simões \& Tupinambá } \\
\text { Simões \& Tupinambá } \\
\text { C. Pinto \& O. Pereira } \\
\text { C. Pinto } \\
\text { Simões \& Tupinambá } \\
\text { Simões \& Tupinambá } \\
\text { Simões \& Tupinambá } \\
\text { Simões \& Tupinambá } \\
\text { Simões \& Tupinambá } \\
\text { Simões \& Tupinambá }\end{array}$ \\
\hline
\end{tabular}

\section{Conclusões}

1. Depois que o sinal de Romaña \& Mazza (edema palpebral) foi conhecido pelos médicos dos postos de higiene e pelos clinicos do interior do Estado do Rio Grande do Sul (Brasil), os casos agudos da Tripanosomiasis cruzi ou doença de Carlos Chagas passaram a ser registrados com freqüência naquele Estado.

Também o conhecimento dêste importante sinal por parte das pessoas leigas tem concorrido para o diagnóstico da referida doença.

2. Os Triatomídeos de hábitos domésticos (Triatoma infestans etc.) são encontrados em quantidade impressionante sob os colchões (Fig. 16) das casas de alvenaria em qualquer época do ano, inclusive durante o inverno, em região onde a temperatura ambiente cai abaixo de zero grau centigrado ( $\mathrm{Fi}$ guras 7 11).

Êste fato modifica o conceito epidemiológico atual da doença de Carlos Chagas referente aos domicilios infestados pelos Triatomideos até então observados somente nos ranchos (cafuas) de barro ou de pau a pique intrometidos nas frestas das paredes de tais habitações.

3. Os triatomídeos (Triatoma infestans) são encontrados infectados pelo Trypanosoma cruzi em ranchos destruídos há mais de dois meses em região de campo aberto onde a temperatura ambiente cai abaixo de zero grau centigrado. Esste fato foi demonstrado experimentalmente e tem grande importancia epidemiológica.

4. De 1939 a julho de 1946 foram observados 73 casos de doença de Carlos Chagas em regiões fisiográficas diferentes do Estado do Rio Grande 
do Sul. Apenas à beira mar não foram registrados os transmissores naturais da doença de Carlos Chagas.

5. O Eıtriatoma rubrovaria é encontrado nos buracos de Dasipodídeos (Dasypus hybridus) em campo aberto, durante o inverno, em temperatura ambiente abaixo de zero grau centigrado, sendo a segunda espécie observada em condições naturais sugando os Dasipodídeos.

Agradecimento. Aos Drs. D. Bottini e J. Guaraní de Sousa pelo muito que nos auxiliaram neste trabalho, aqui registramos os nossos cordeias agradecimentos.

\section{BIBLIOGRAFIA}

BOLSSON, R. A.

1943. Dois casos de moléstia de Chagas em Nova Palma. Municipio de J. de Castilhos, Rio Grande do Sul, Arquivo de Biol. São Paulo. 27 (256) : 95-96. Figs. 1-2.

Caldas, J. A. L. Tupy

1942. Esbôç̧o Geográfico do Rio Grande do Sul. In Brasilia Aeterna. Rio Grande do Sul. Imagem da Terra Gaúcha. Editora Cosmos Ltda. P. Alegre: 59-88.

MedvedovsKi, V.

1945. Três casos de doença de Chagas no Rio Grande do Sul. Arq. de Clinica. 1(3): 379-382. Fig. 1-2.

MedvedovsKi, V.

1946. Notas sôbre quatro novos casos agudos de moléstia de Chagas no Rio Grande do Sul. Arq. Dep. Est. Saude Rio Grande do Sul. 6:189-192. Figs. 1-2.

PINTO, C.

1941. Pesquisas sôbre Parasitologia humana e animal no Rio Grande do Sul. Arq. Dep. Est. Saude, R. G. do Sul. 2:73-91.

PINTO, C.

1942. Ttipanosomiasis cruzi (Doença de Carlos Chagas) no Rio Grande do Sul. Mem. Inst. Osw. Cruz. 37 (4) : 443-537. Est. 1-57. Rio de Janeiro.

Salis, E.

1945. Primeiro caso identificado de mal de Chagas na zona Sul do Brasil. Imp. Medica. 21 (378): 121 . Rio.

Simões, A. J. P. \& Tupinambí, A. A.

1942. Investigações epidemiológicas sôbre a Doença de Chagas no Rio Grande do Sul. Arq. Dep. Est. Saude Rio Grande do Sul. 3 : 143-149. 1 fig. e 1 mapa.

TORRES, C. B. Magarinos

1915. Alguns fatos que interessam à epidemiologia da moléstia de Chagas. Mem. Inst. Osw. Cruz. 7 (2) : 120-138. 


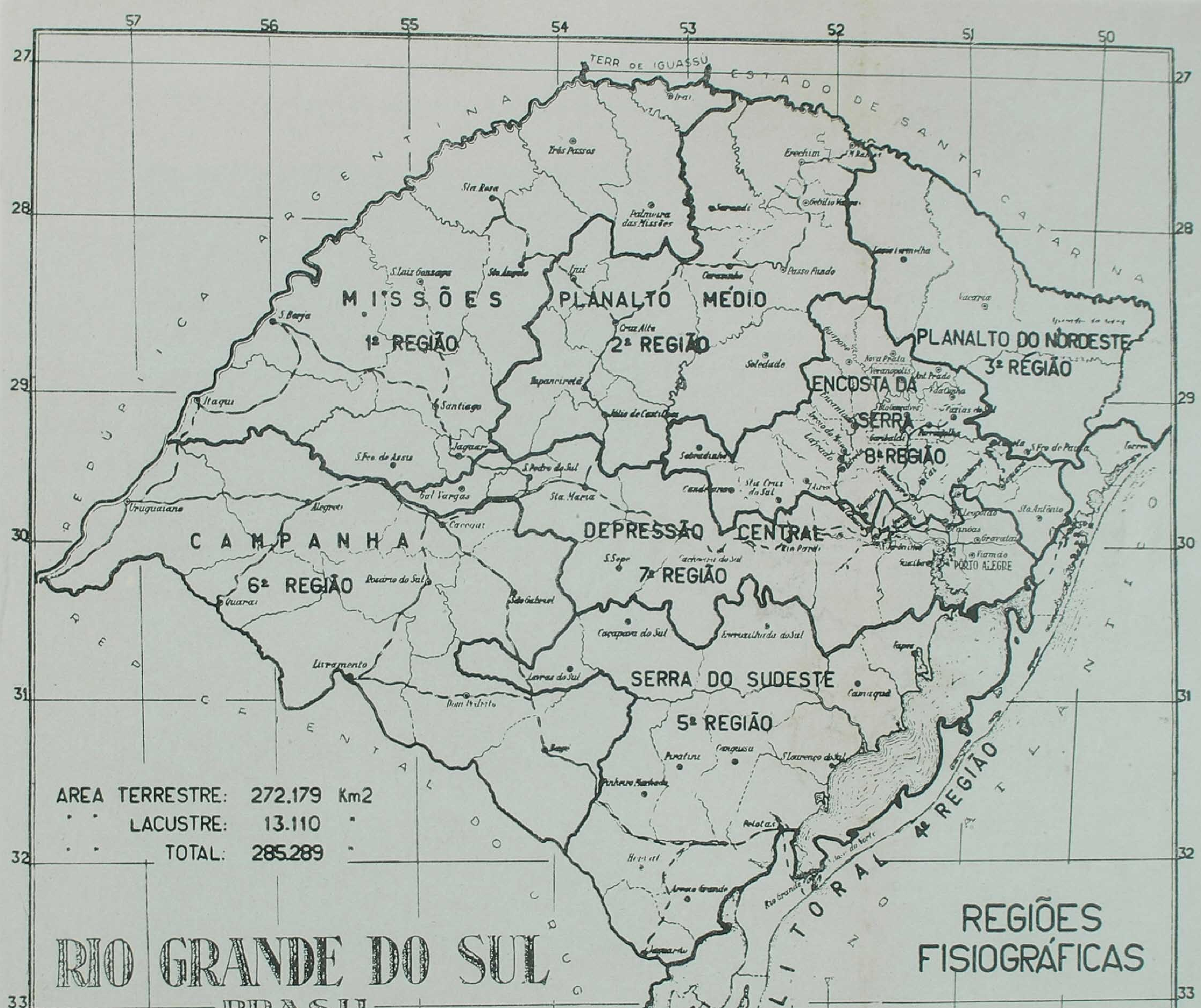

IBHE 5 S月-

POPULACÃO DO ESTADO: $3.523 .428 \mathrm{Hab}$.

PO̊RTO ALEGRE - CIDADE: 294.908 "

MUNICIPIO: 303.795

CALCULADA ARITMETICAMENTE E

AJUSTADA PARA I\& DE JULHO, 1946
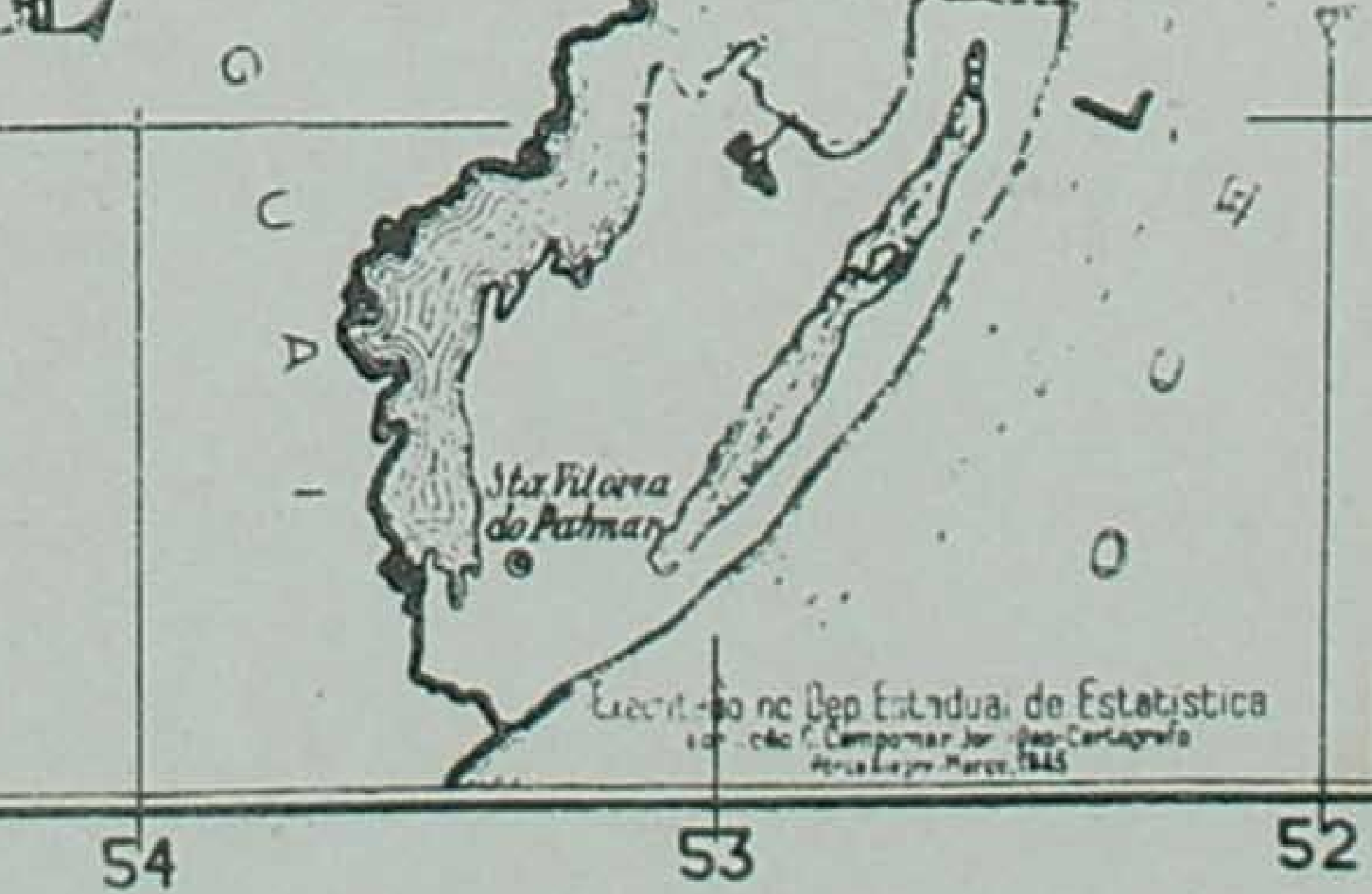

Sencico de Epidectidage 


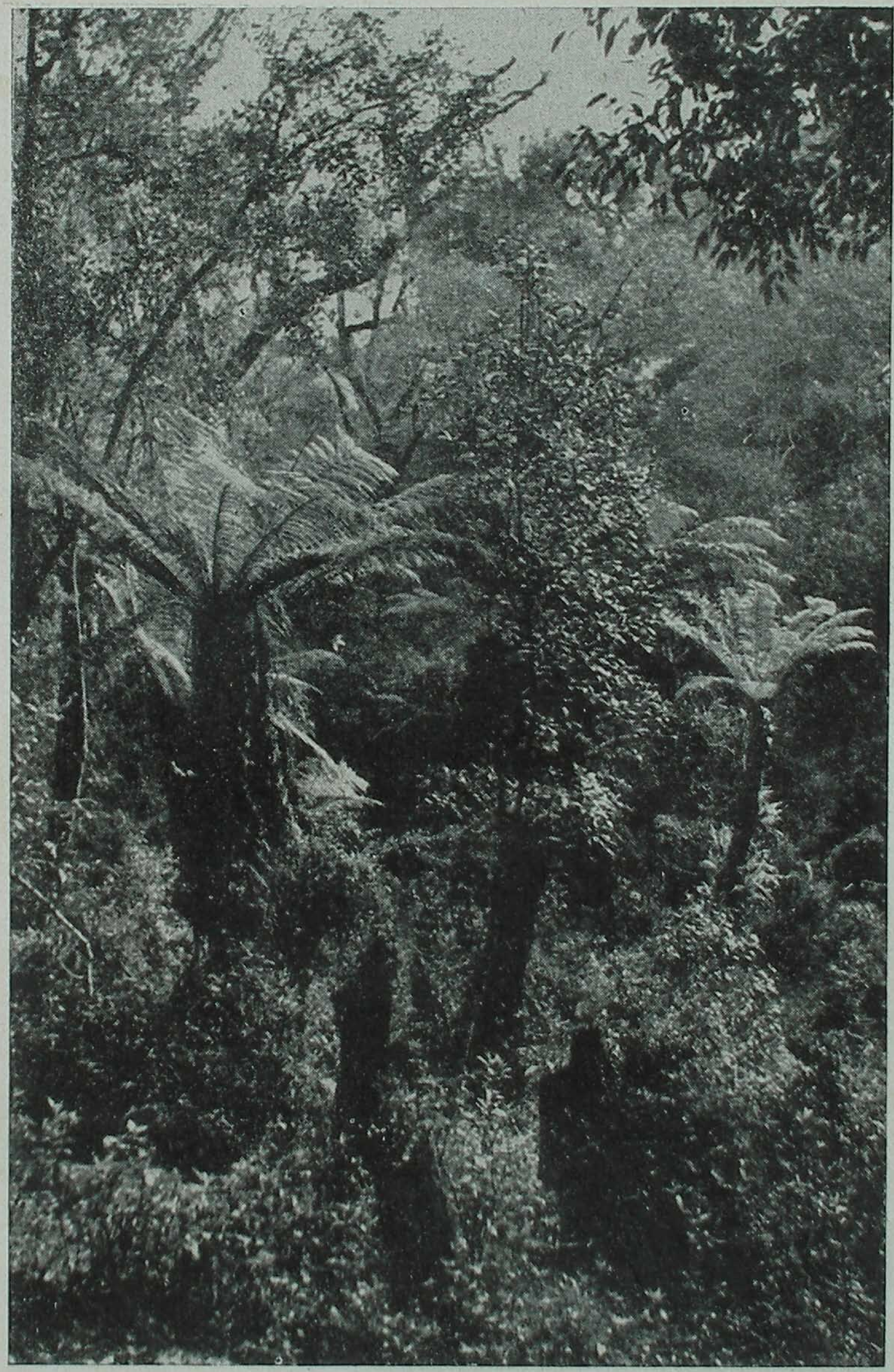

Fig. 2

Nas regiões de matas a cerca de 900 metros de altitude com temperatura cahindo a menos 6 ou menos 8 gráos abaixo de zero foi encontrdo o Panstrongilus megistus que resiste a essas temperaturas e procria nos domicílios de barro Foto Studio os Dois. 


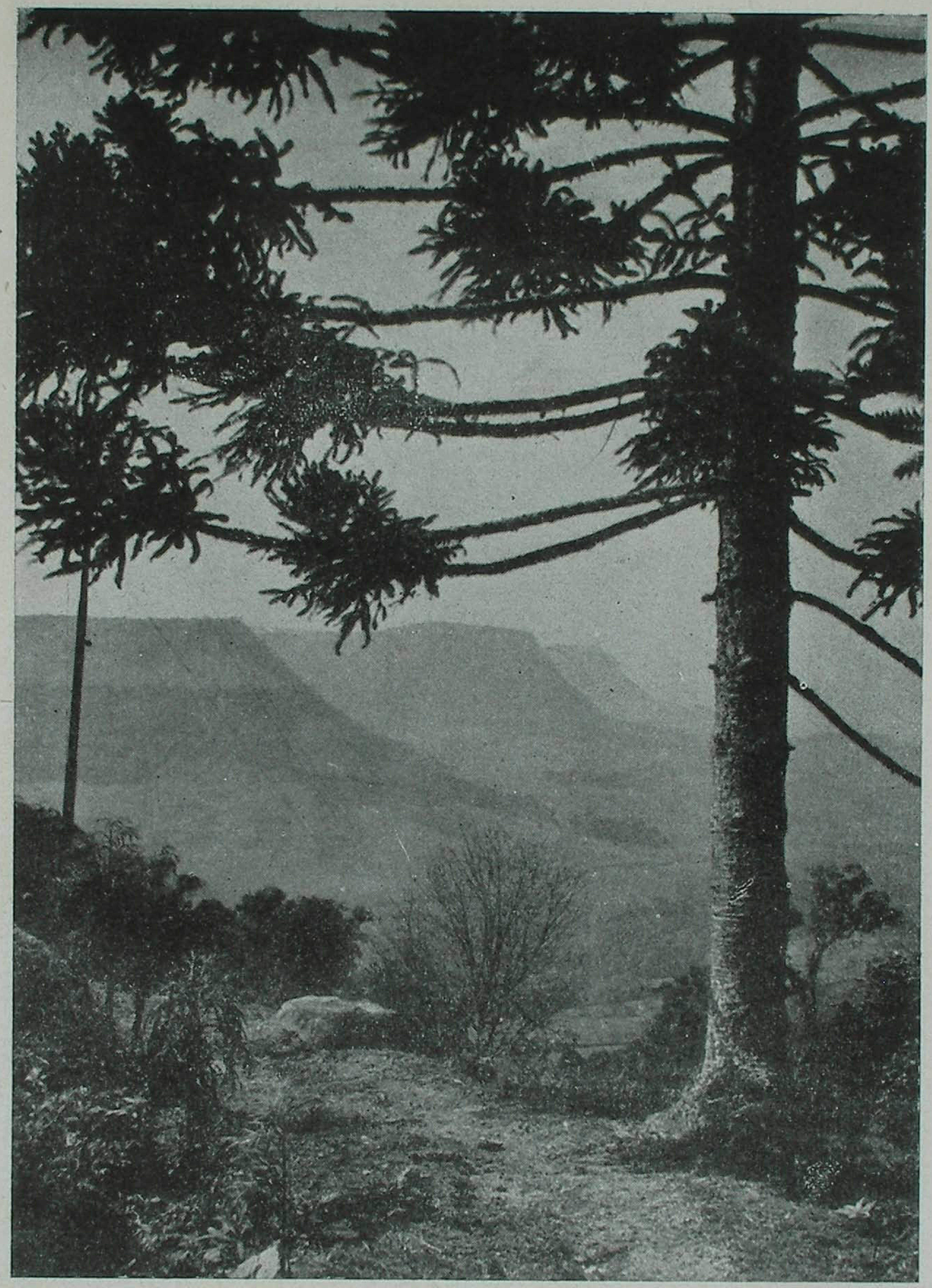

Fig. 3 .

Zona montanhosa do norte do Estado do Rio Grande do Sul onde no inverno a temperatura cahe a menos 6 ou menos oito gráus centígrdos. Em certos municípios dessa região é encontrado o Panstrongylus megistus e o Triatoma infestans. 


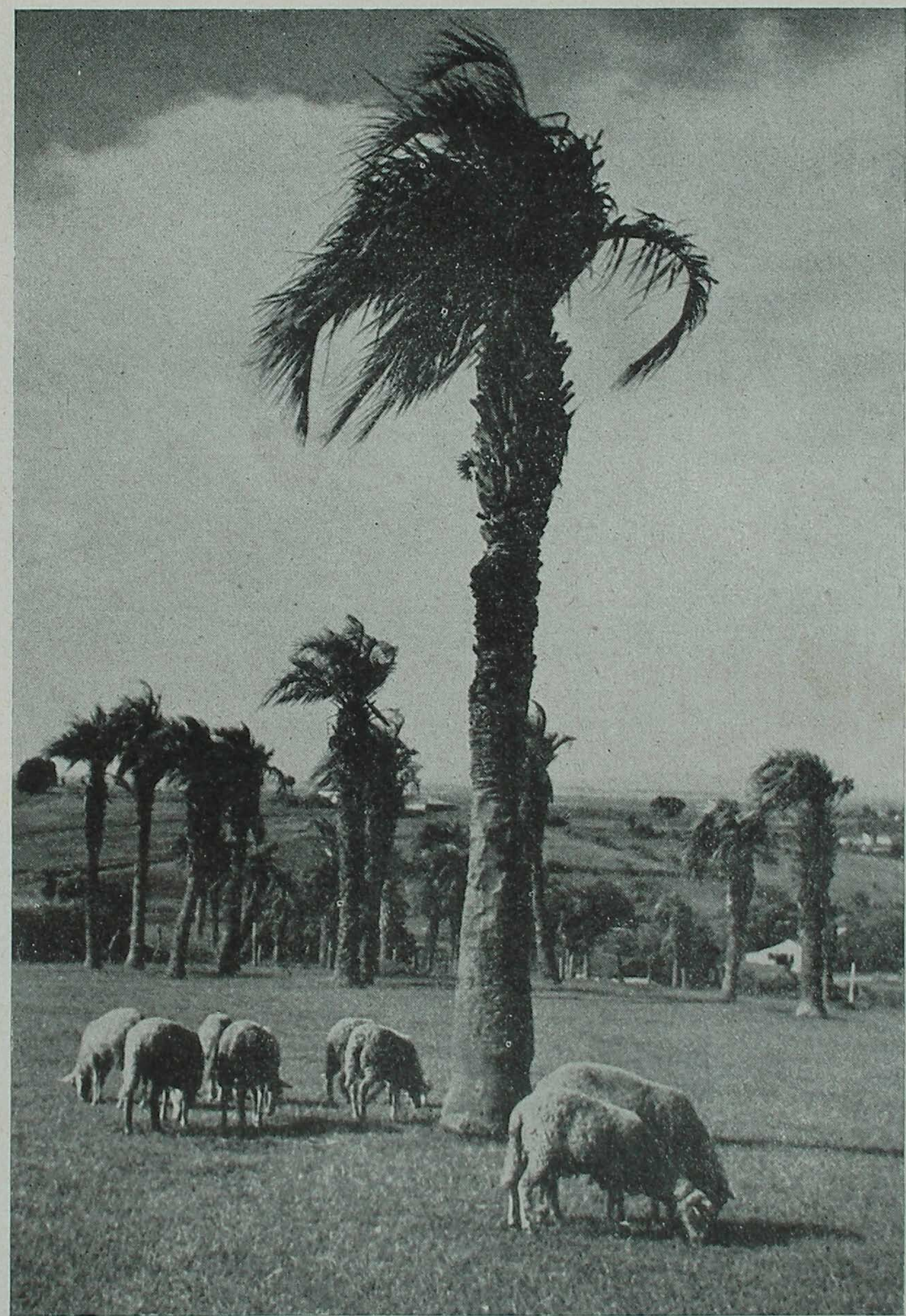

Fig. 4.

Região de campos descobertos onde é encontrado o Triatoma infestans em grande quantidade nos domicílios de muitos municípios do Rio G. do Sul. 


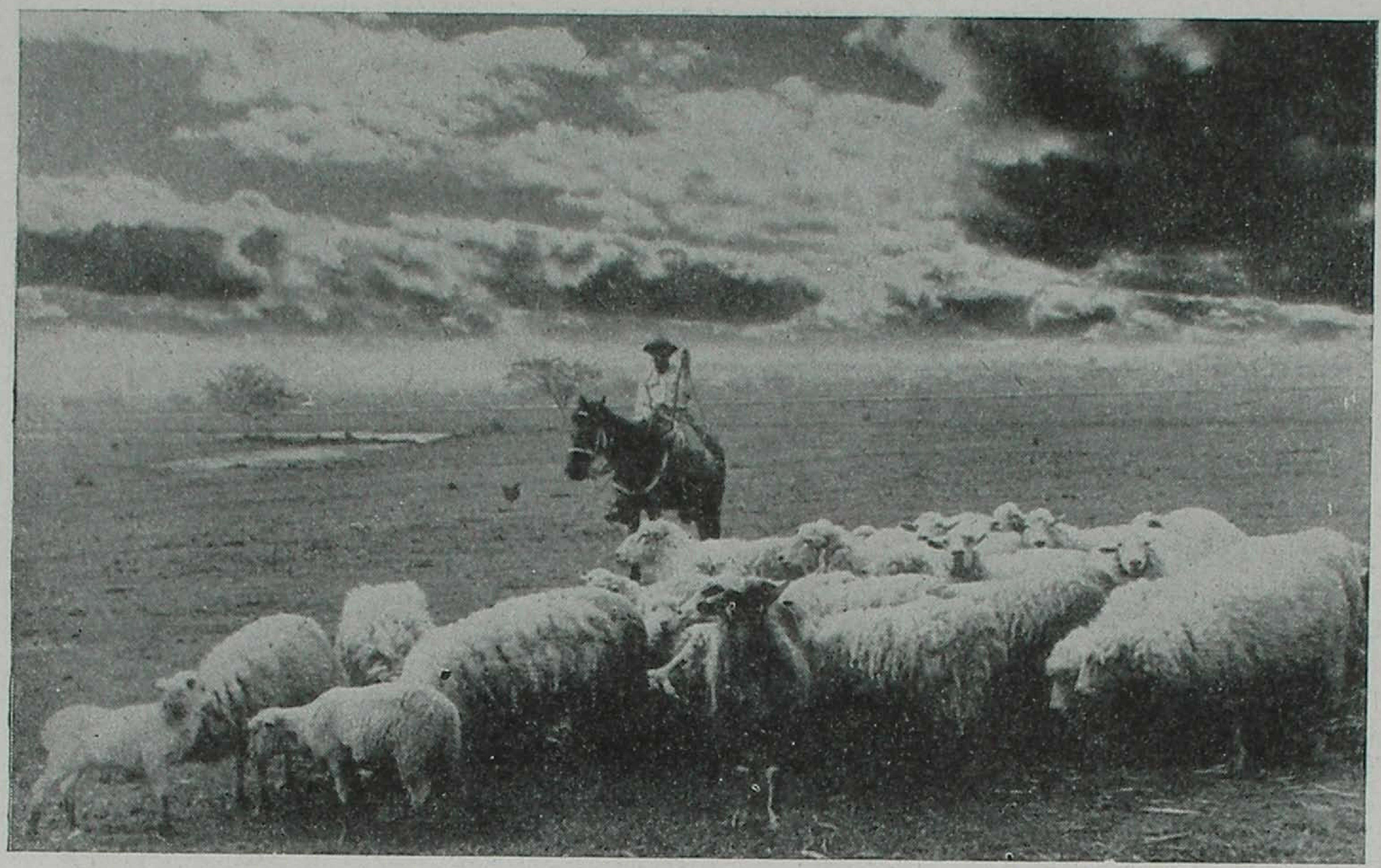

Fig. 5 .

Lampos descobertos onde é frequente o tatú mulita Dasypus hybridus em cujas locas encontramos o Eutriatoma rubrovaria. Este Triatomideo vive de preferência sob as pedras das zonas de campos abertos?

Foto Studio os Dois.

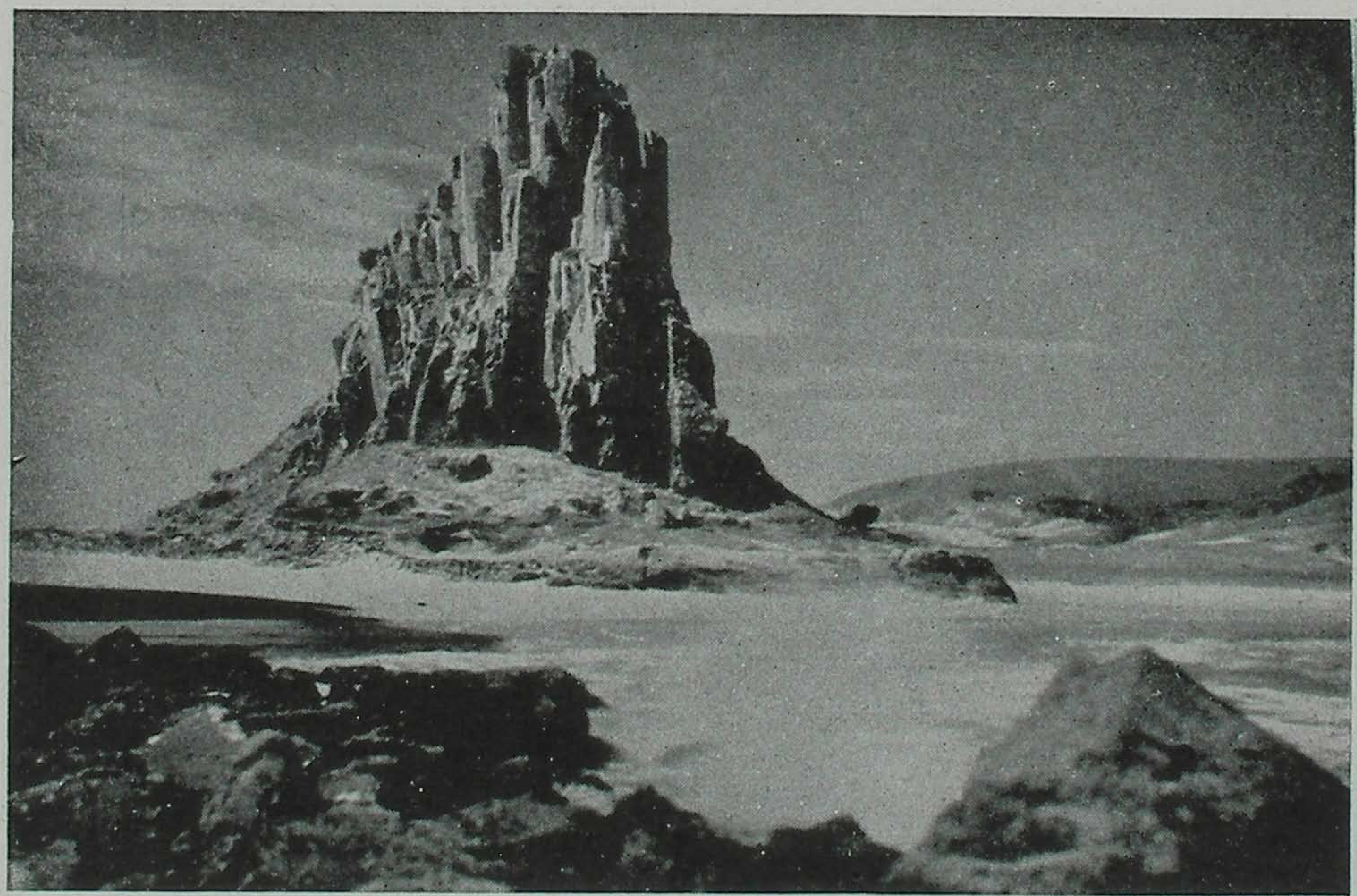

Fig. 6 .

Fotografia de Torres á beira mar. Até a presente data os Triatomideos não foram encontrados nessa região fisiográfica do Rio Grande do Sul. 


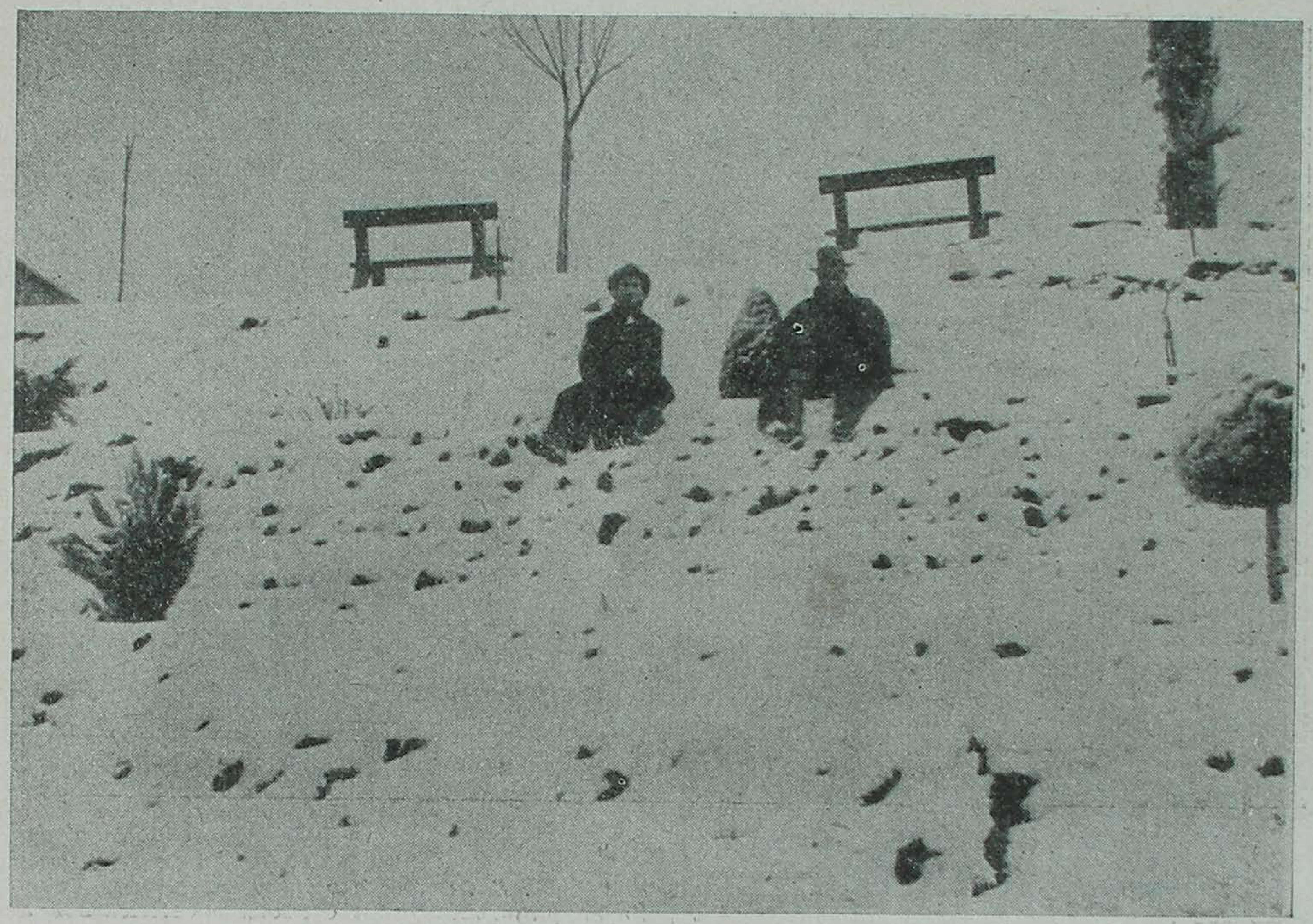

Fig. 7

As nevadas nos municípios do norte do Rio G. do Sul são frequentes no inverno cahinåo a temperatura a menos seis ou menos oito gráus centigrados, como por exemplo em $\mathrm{S}$. Francisco de Paula, Taquara etc., onde encontramos o Panstrongylus megistus que resiste e procria nessas regiões. A foto acima é de S. Francisco de Paula a cerca de 900 metros acima do nivel do mar.

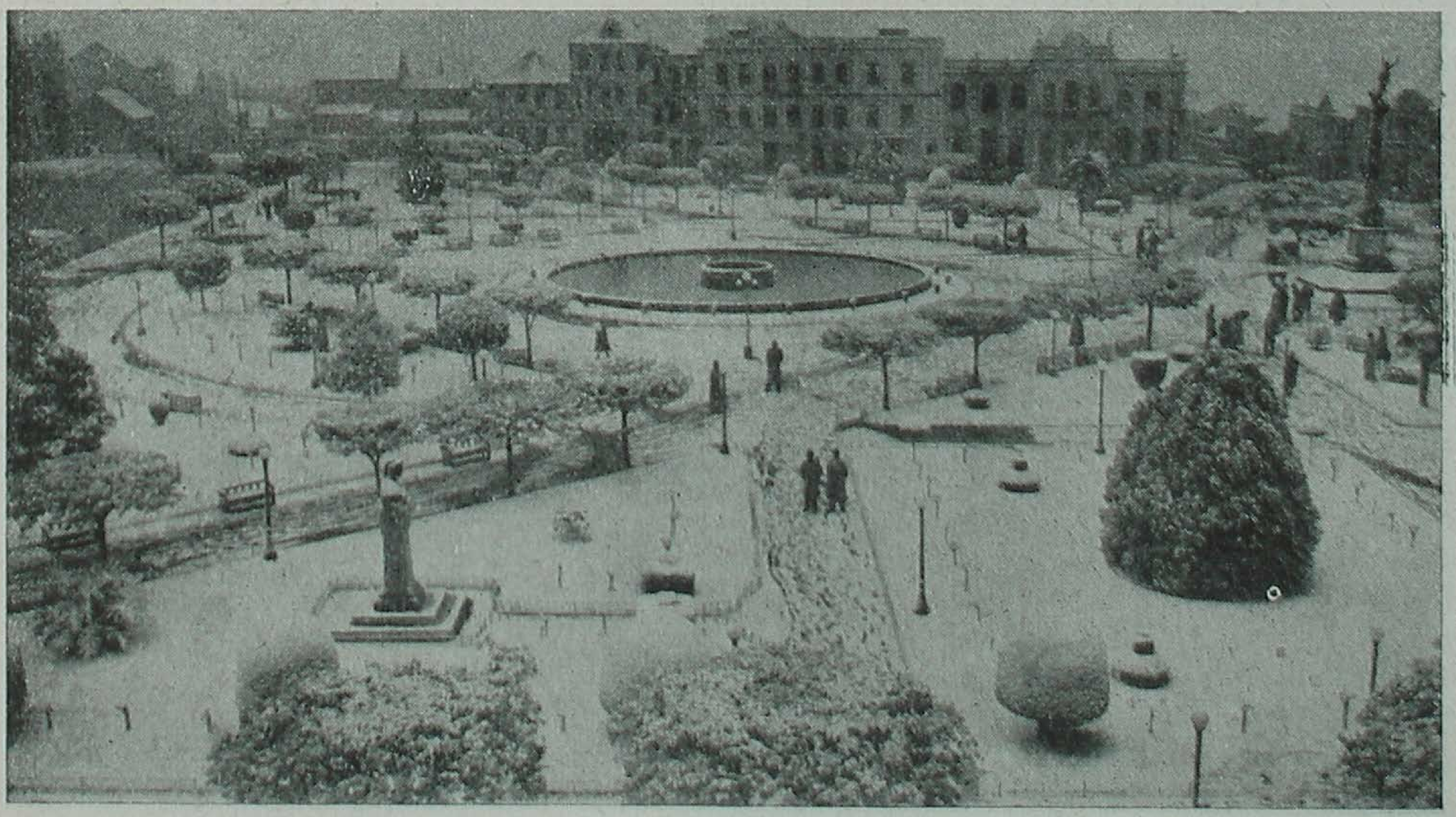

Fig. 8 .

Fotografia tomada na cidade de Caxias do Sul, R. S., durante o inverno. Esta eidade está localizada na região fisiográfica chamada Encosta da Serra a cerca de 900 metros de altitude. As nevadas são frequentes nessa região, cahindo a temperatura a menos 6 gráus centigrados. Os Triatomídeos (Panstrongylus megistus) são encontrados nessa temperatura extremamente fria e os exemplares de Triatoma infestans nessas condições apresentam-se infectados pelo Trypanosoma cruzi conforme demonstramos experimentalmente. 


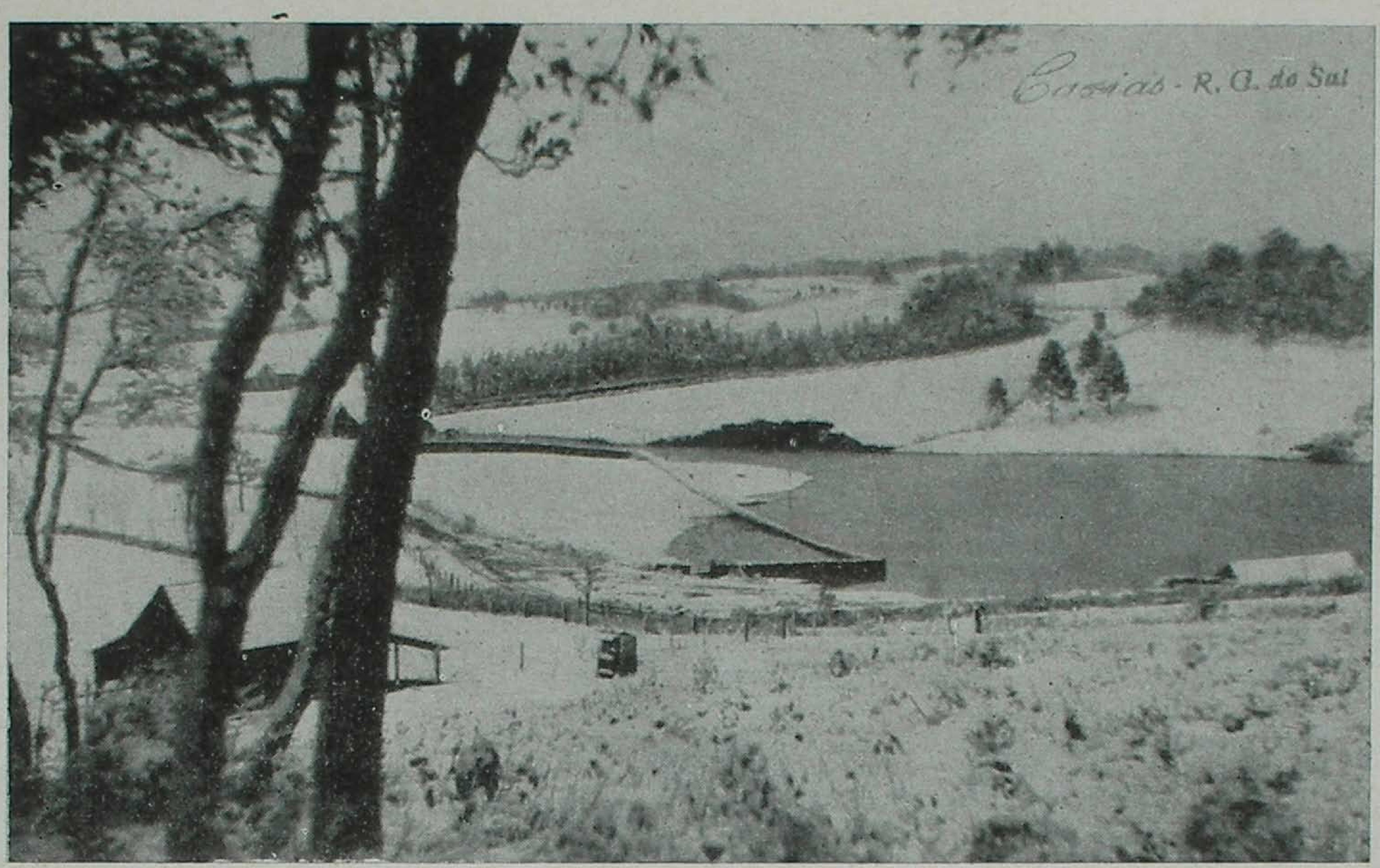

Fig. 9

Fotografia tomada no município de Caxias do Sul, R. S., durante o inverno onde os Triatomideos resistem e apresentam-se infectados pelo Trypanosoma cruzi conforme verificamos a zero gráu centigrado nos campos do município de Uruguaiana, R. S.

Foto Peremia.

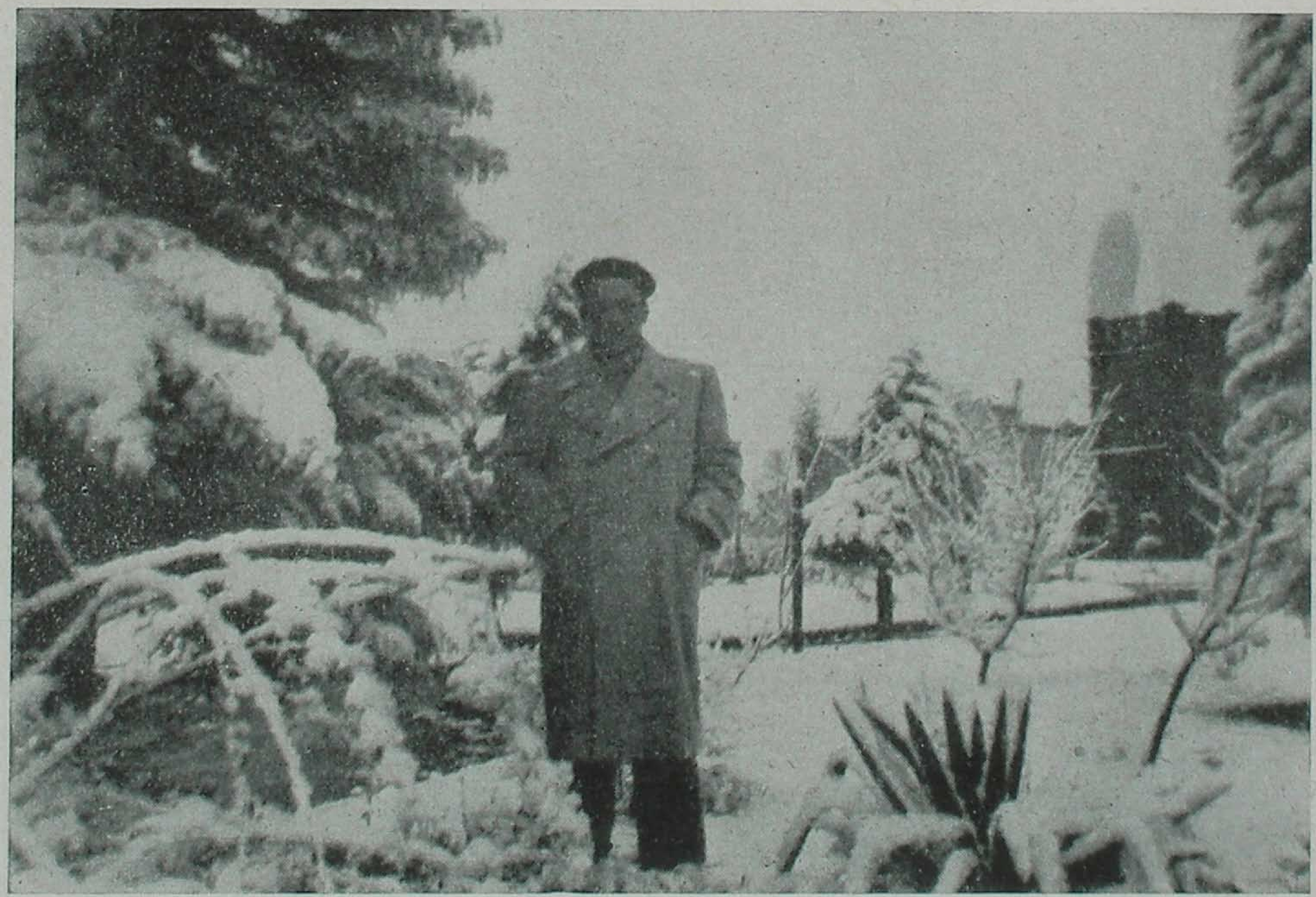

Fig. 10 .

Fotografia tomada no inverno (4 de julho de 1942) na cidade de Passo Fundo, R. G. do Sul pertencente á Região fỉsiográfica do Planalto Médio. 
TEMPERATURAS EM 5 CIDADES DO ESTADO DO RIO G. DO SUL 1942
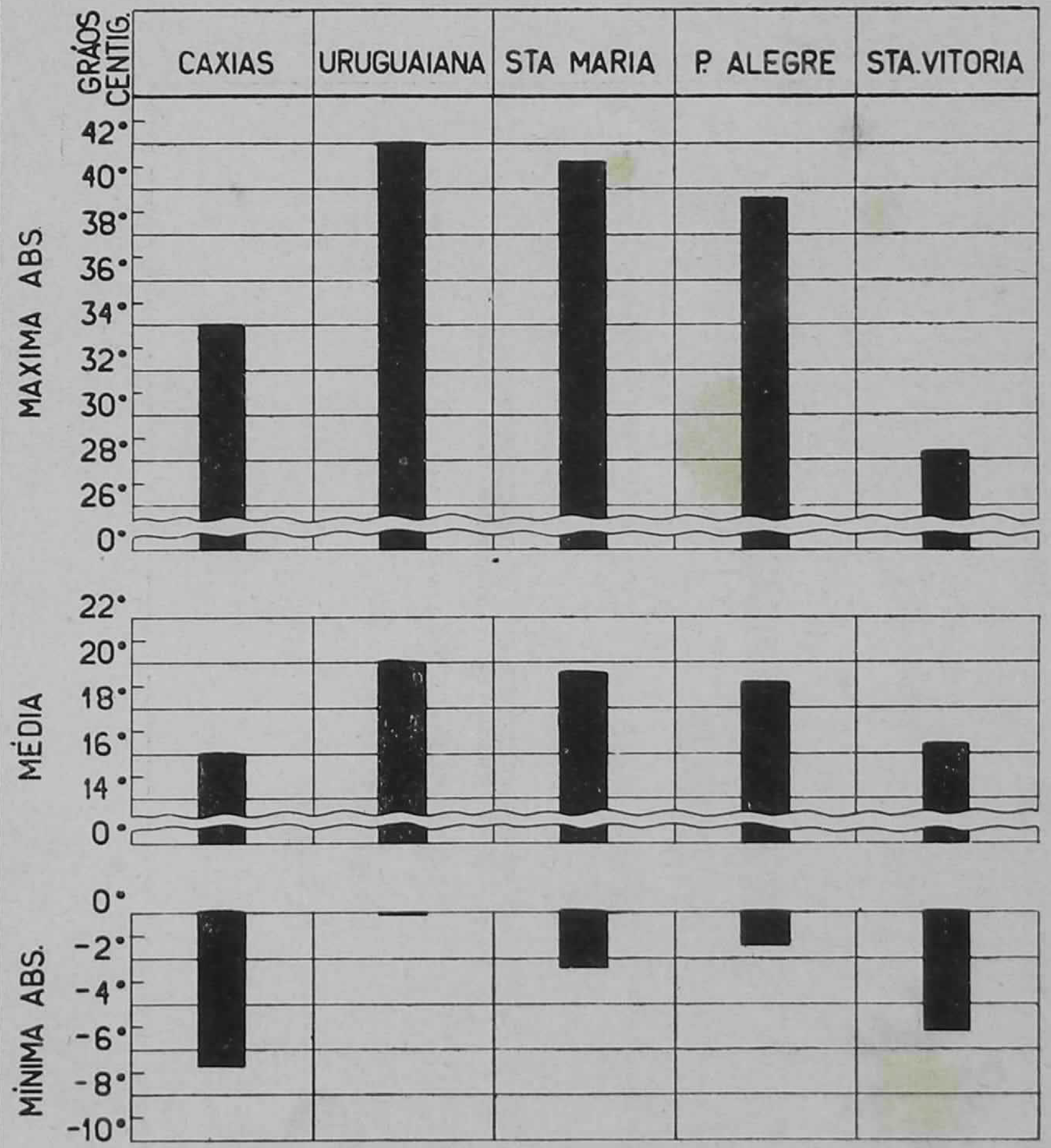
MUNICIPIOS DO ESTAD EM 1942

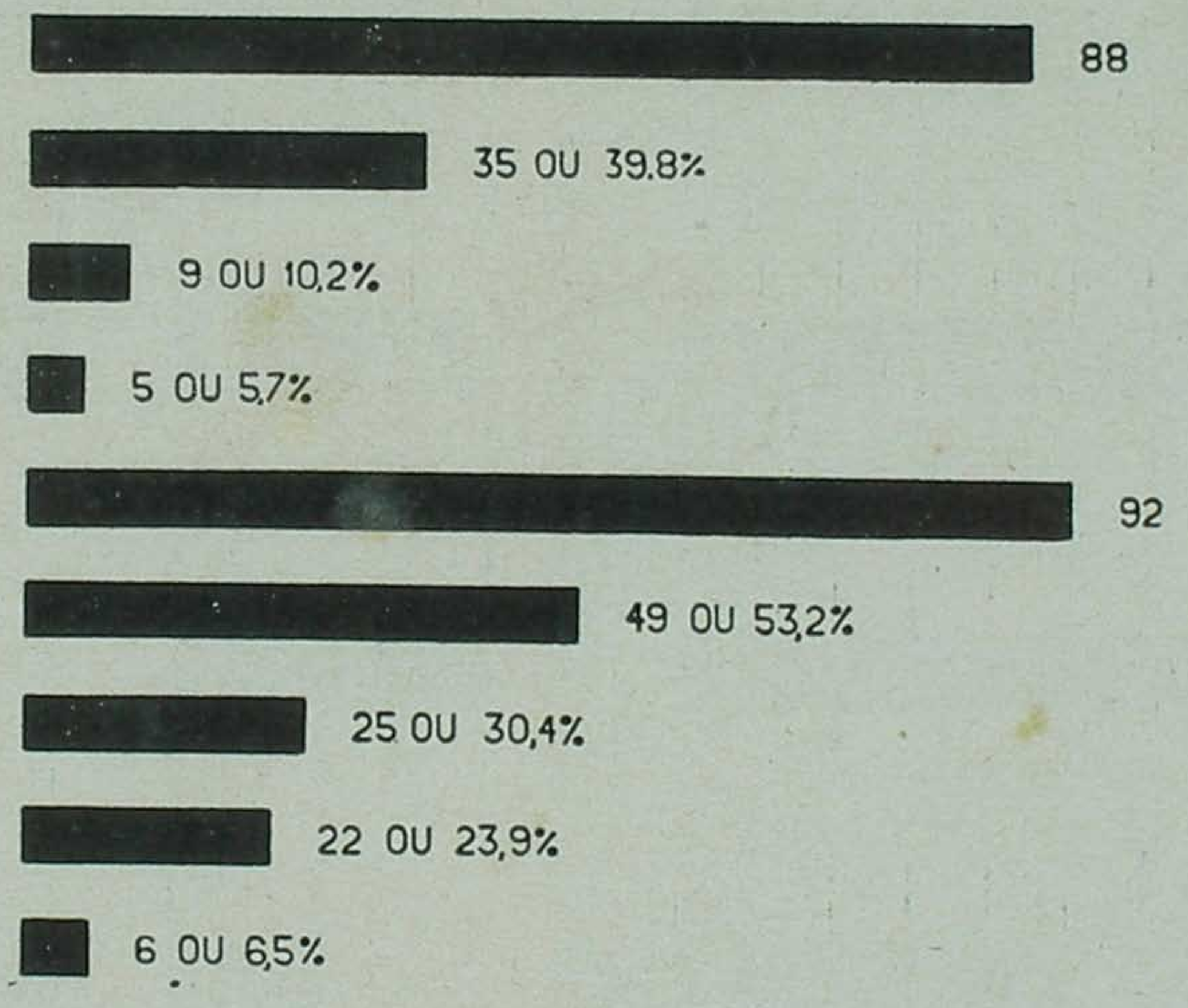

Fig. 13. 


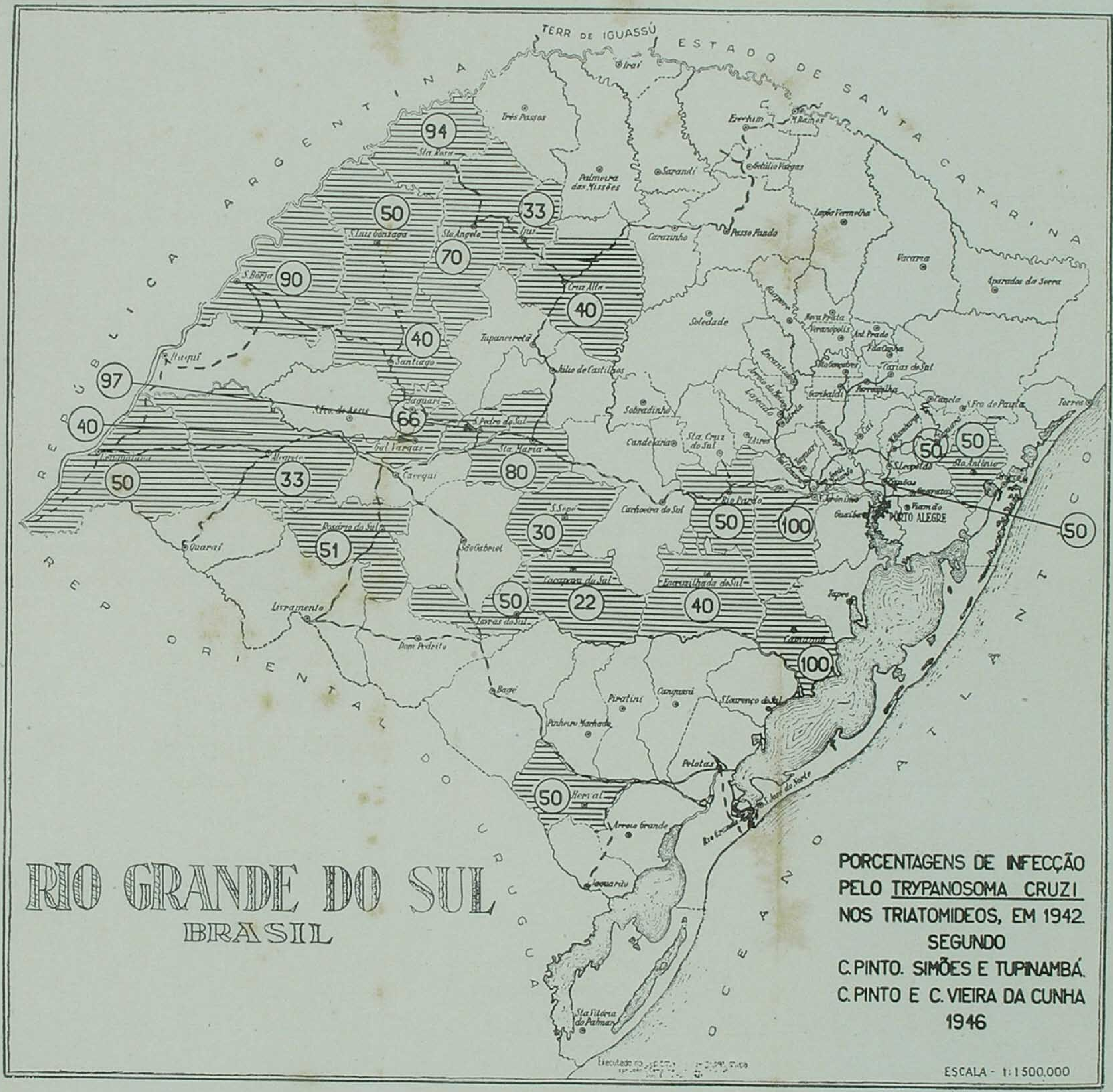

Fig. 12

Municipios do Estado do Rio Grande do Sul, Brasil, indicando as porcentagens naturais de infecção dos Triatomideos peloTrypanosoma cruzi 


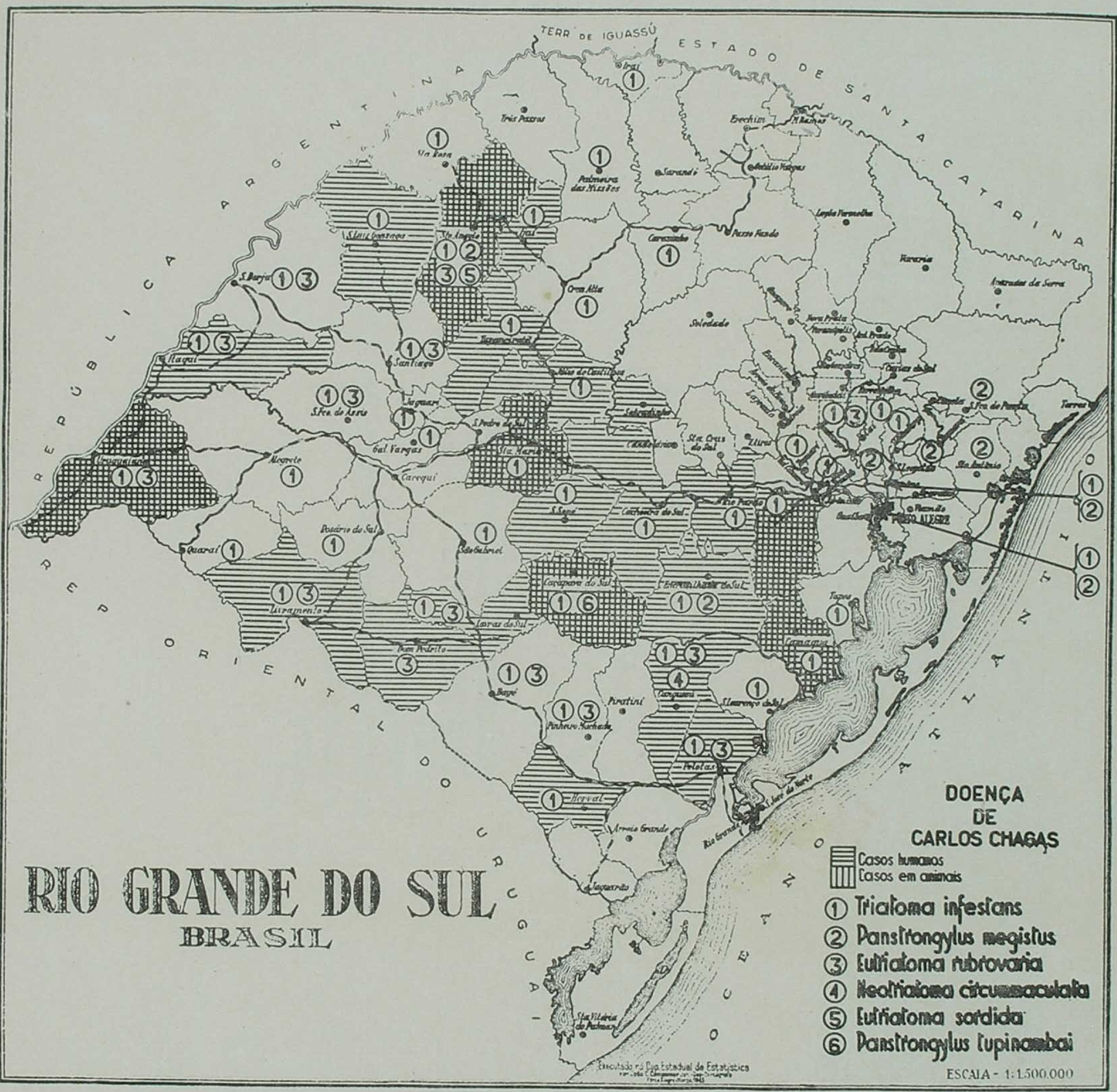

Fig 14 


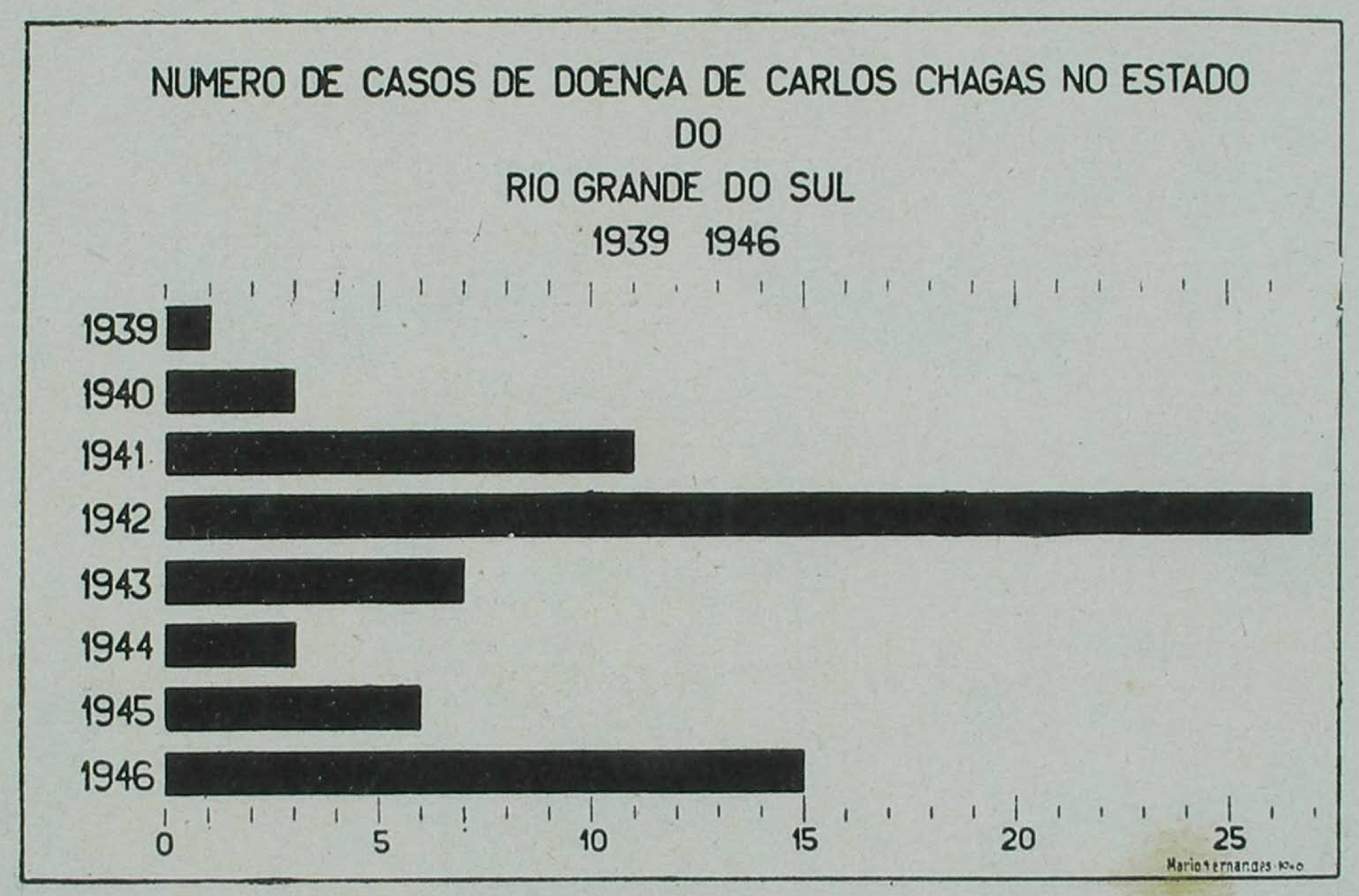




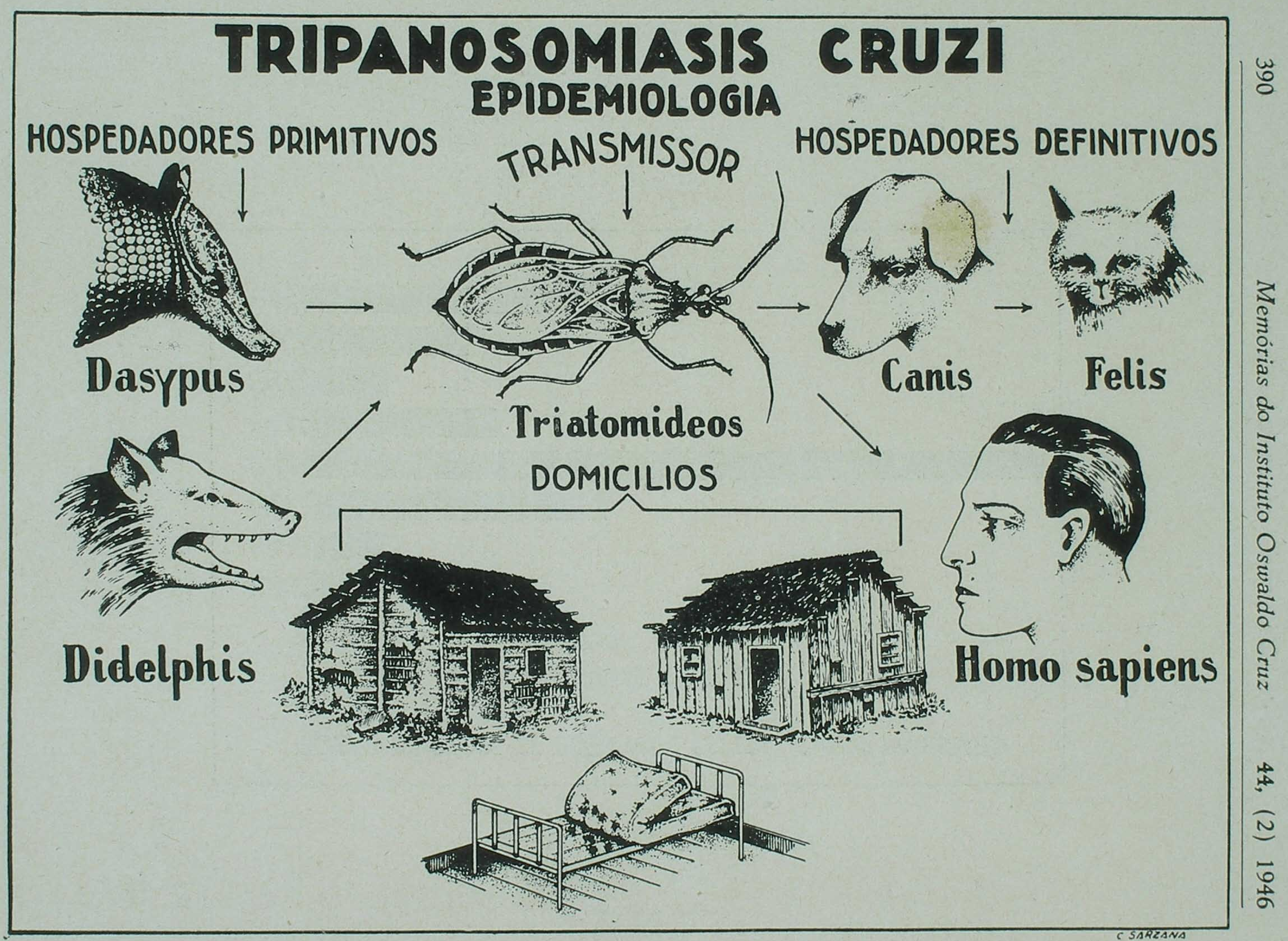




\section{MODO DE TRANSMISSÃO DO TRYPANOSOMA CRUZI AO HOMEM}
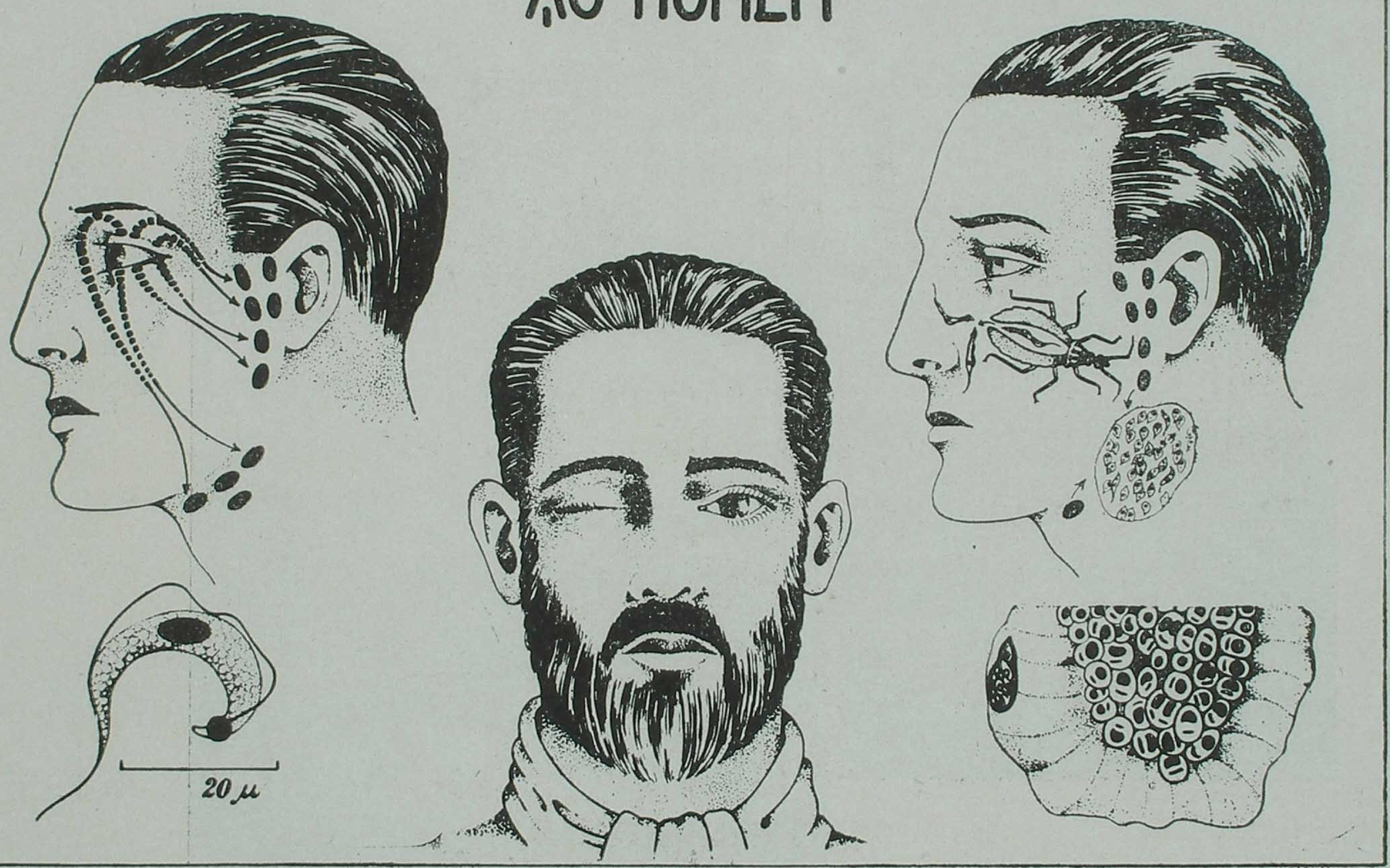


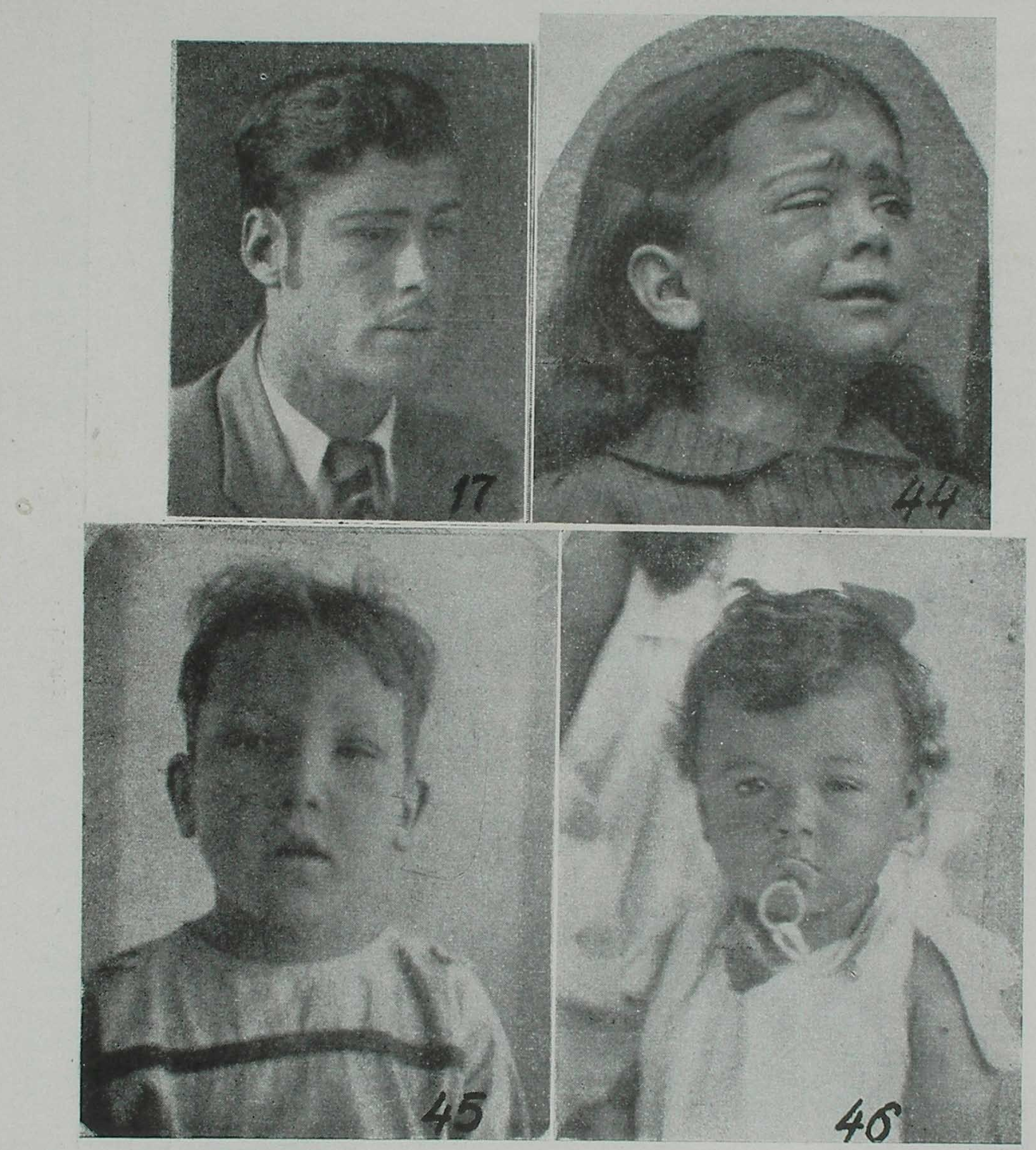

Fig. 18.

Casos agudos de doença de C. Chagas observados no Río G do Sul. O doente n.o 17 é do Dr. Luiz A. Osorio, os demais do Dr. Clovis I. Trindade. Todos com sinal de Romaña \& Mazza unilateral. 
INCIDÊNCIA EM ADULTOS E CRIANÇAS

DOENÇA DE C. CHAGAS NO RIO G.SUL

EPIOEMIOLOGIA

$1939-1946$

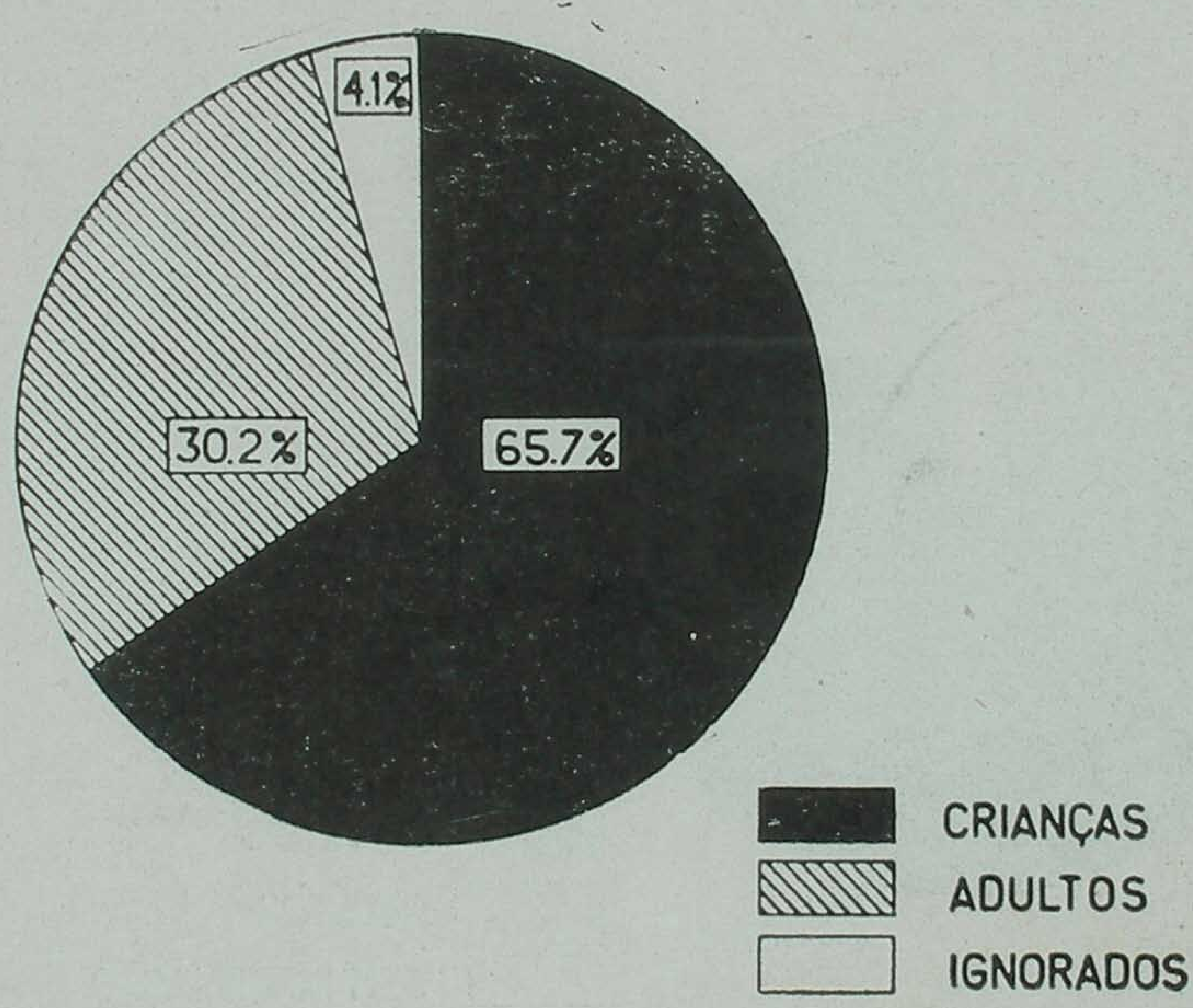

Seav. of EDIOEHIOLOGLA Mario Ternandes 46

Fig. 19. 


\section{CASOS AGUDOS EM ADULTOS E CRIANÇAS}

DOENCCA DE C. CHAGAS NO RIO G.SUL

EPIDEMIOLOGIA

$$
\text { 1939-1946 }
$$

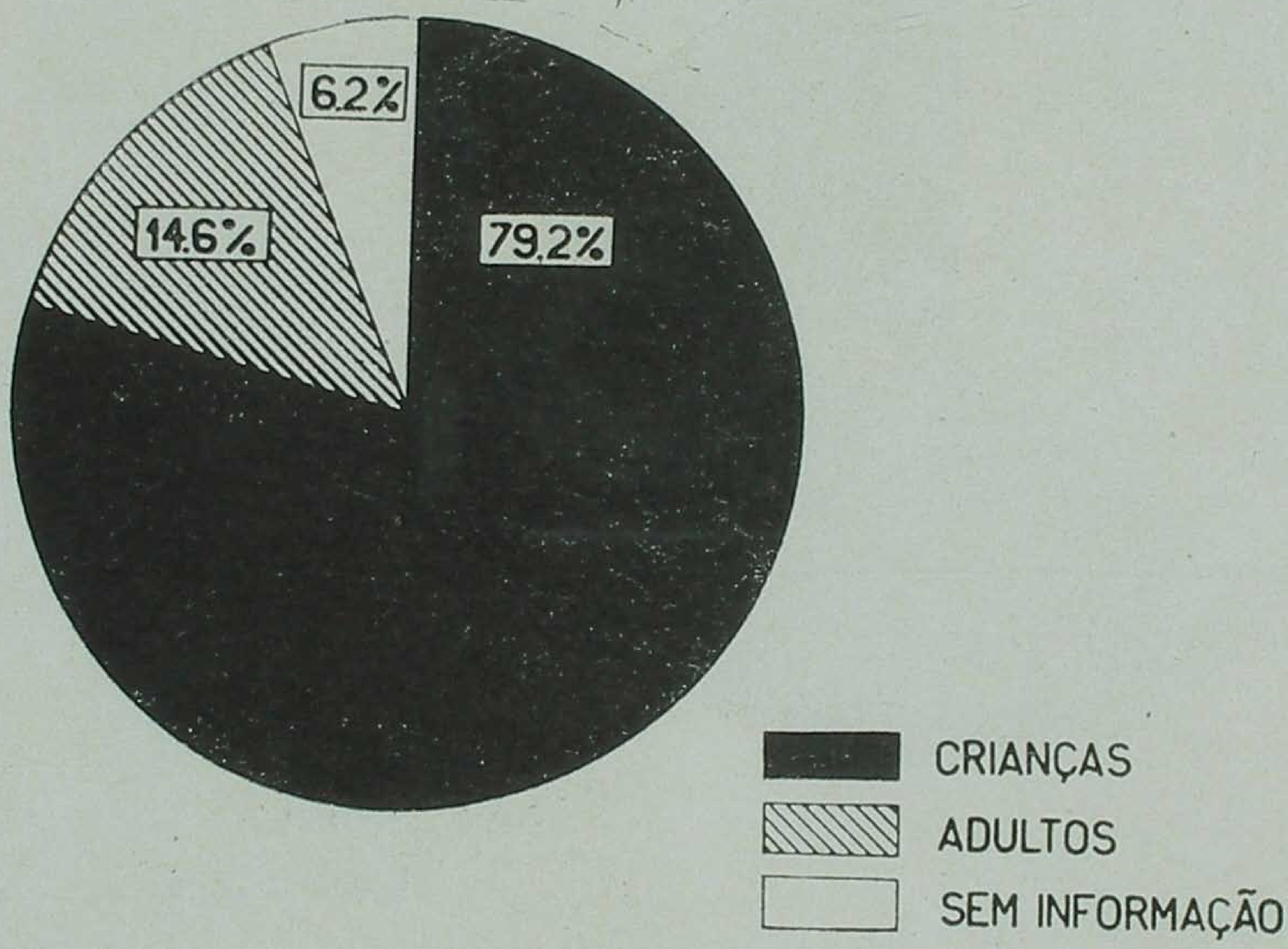

Fig. 20 . 


\section{CASOS CRONICOS EM ADULTOS E CRIANCCAS}

DOENCA DE C CHAGAS NO RIO G.SUL EPIDEMIOLOGIA

$1939-1946$

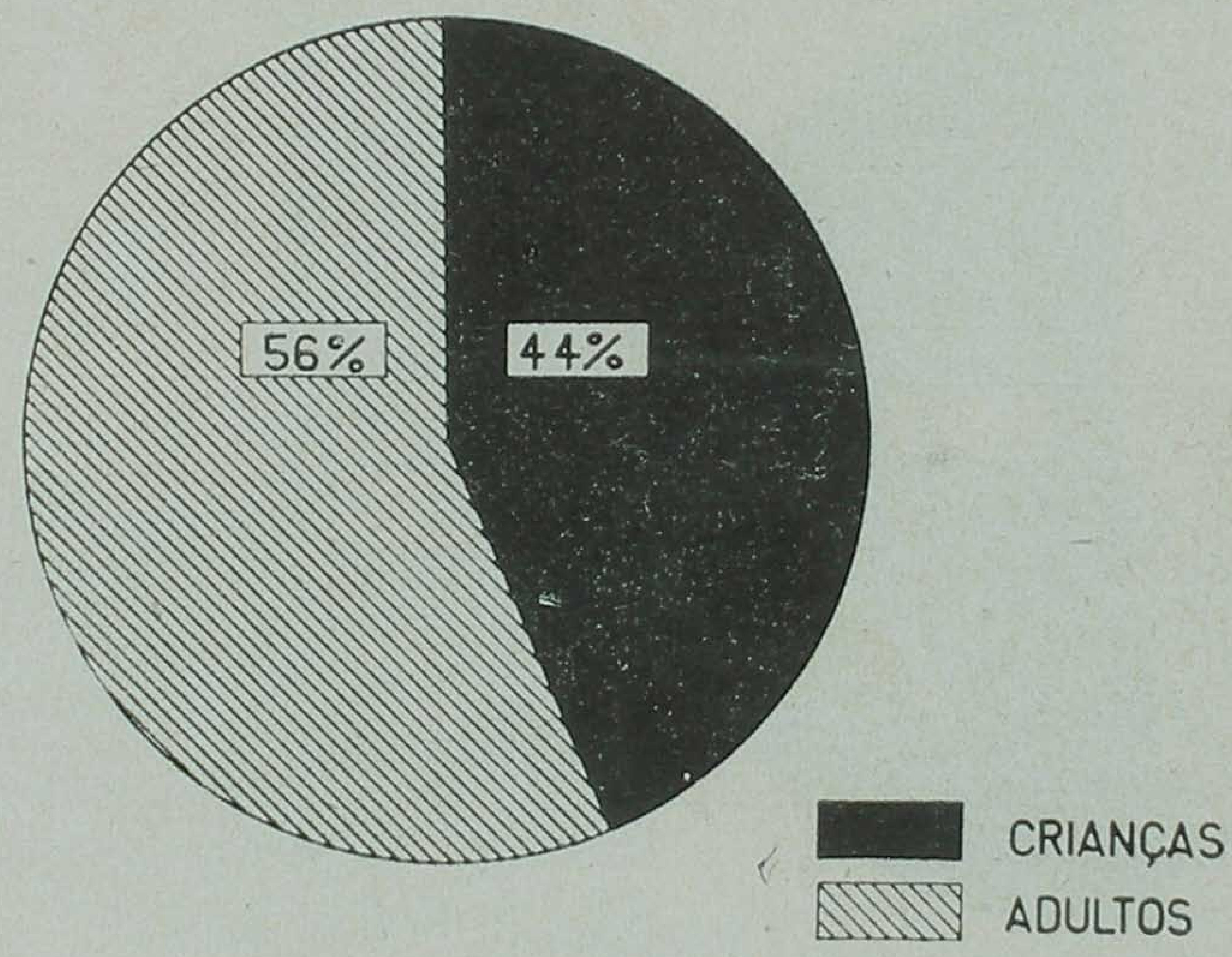

Seav de Edioemiologia

Fig, 21. 


\section{INCIDÊNCIA POR CÔR}

DOENCCA DE C CHAGAS NO RIO G.SUL

EPIDEMIOLOGIA

1939- 1946

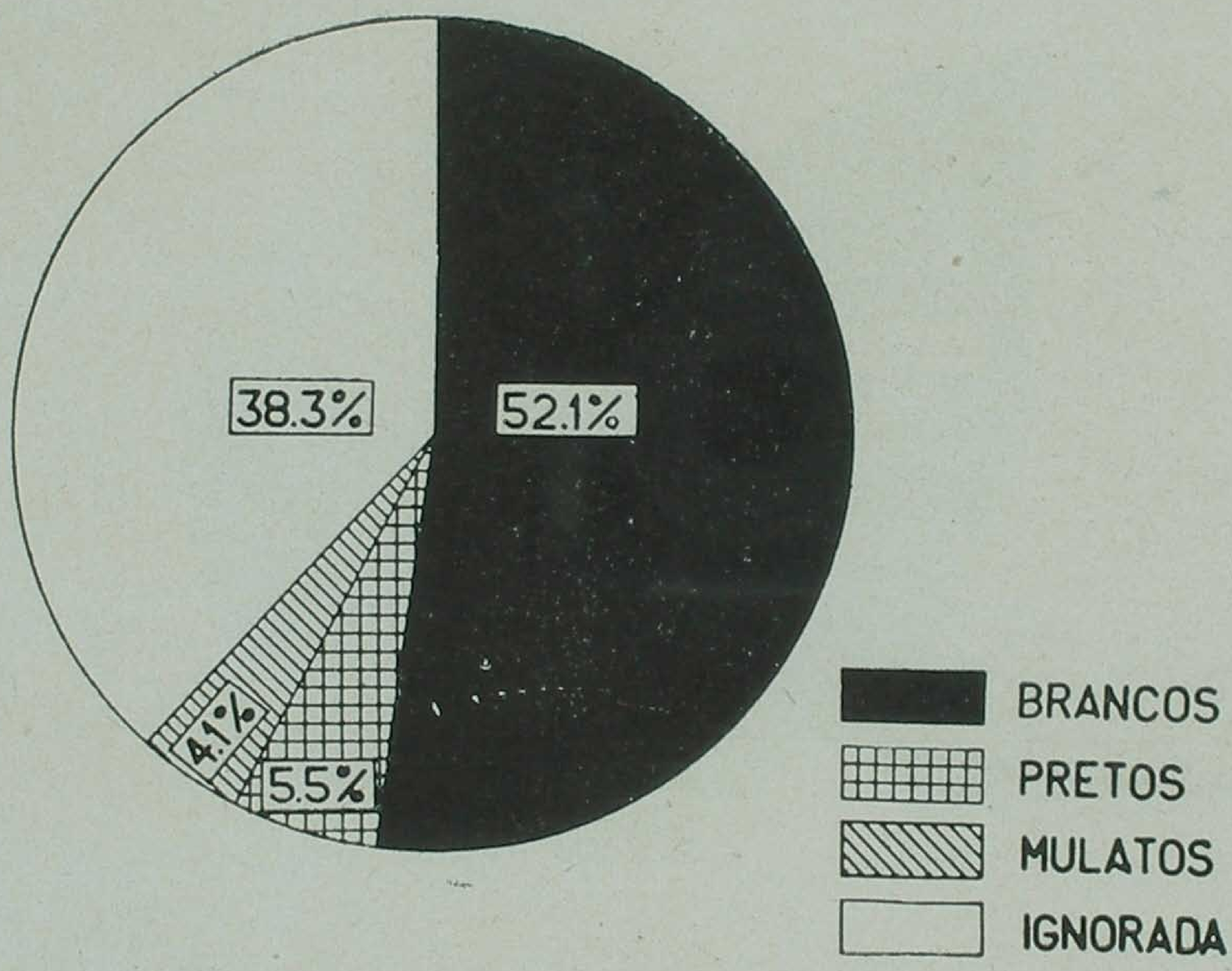

Fig. 22. 


\section{SINAL DE ROMAÑA E MAZZA}

DOENCA DEC. CHAGAS NO RIO G. SUL

EPIOEMIOLOGIA

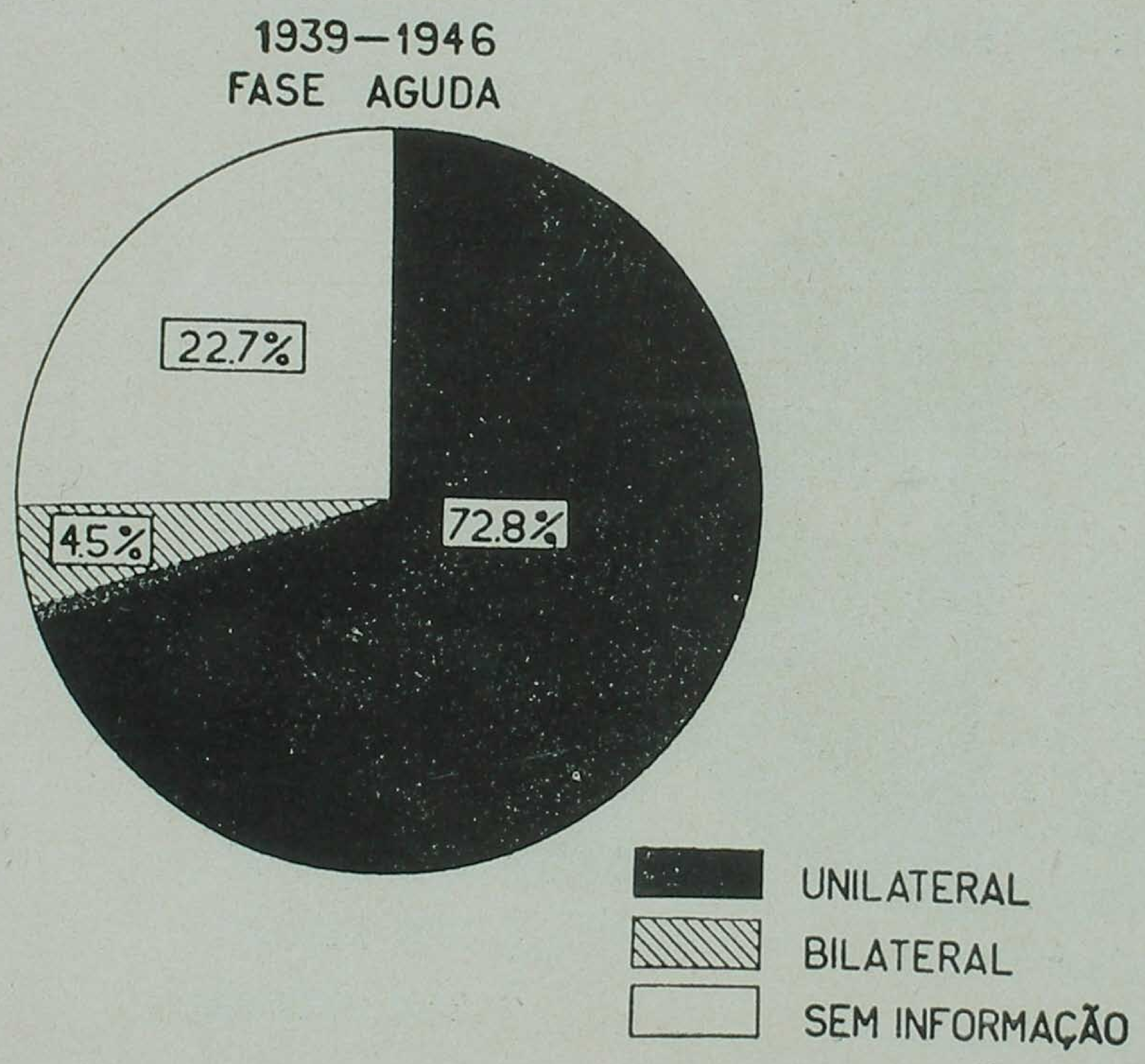

Fig. 23, 


\section{FEBRE EM CASOS AGUDOS}

DOENCAA DE C.CHAGAS NO RIO G. SUL EPIDEMIOLOGIA

$$
\text { 1939-1946 }
$$

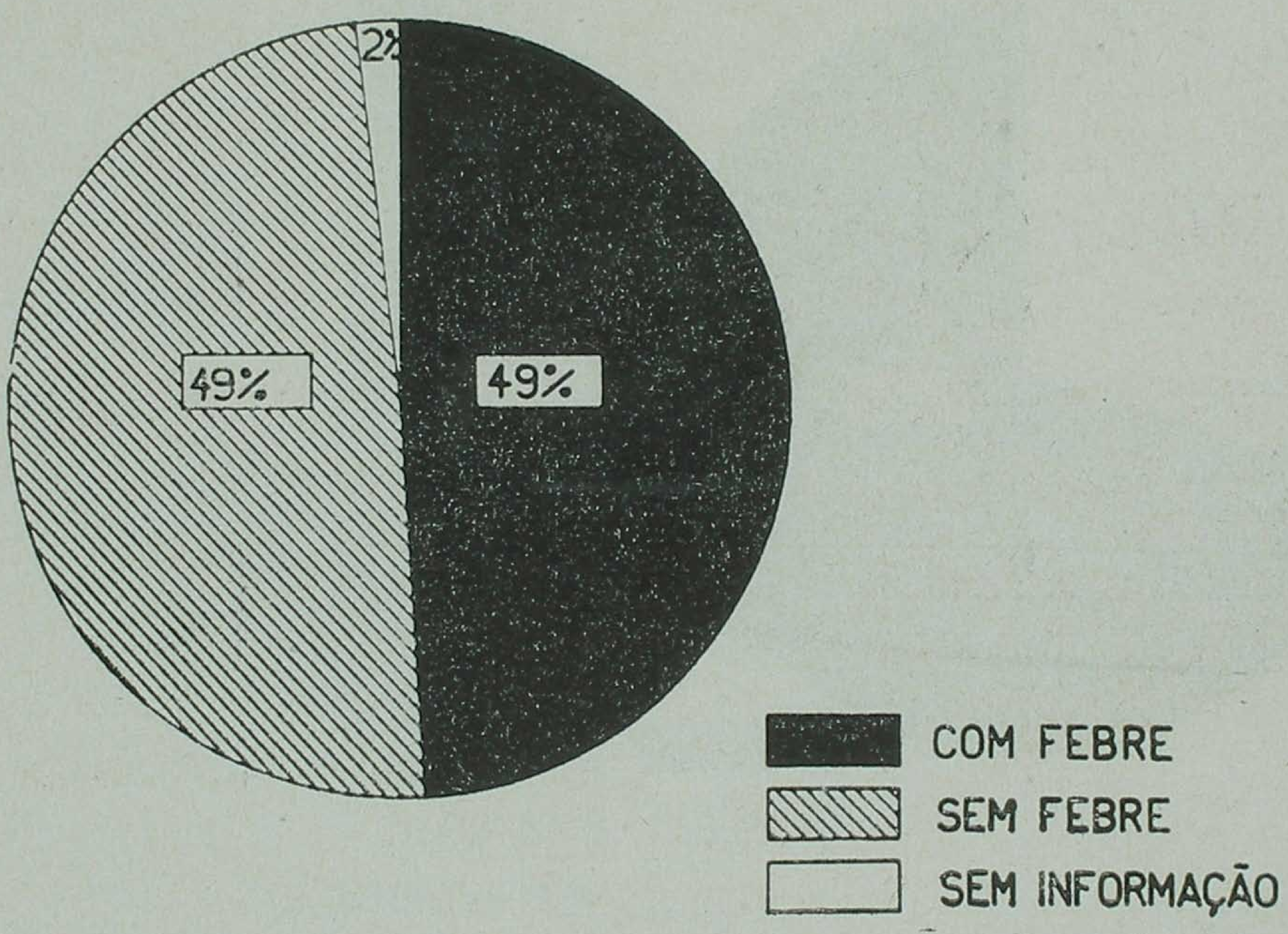




\title{
PERTURBAÇ̃̃ES CARDIACAS
}

\author{
FASE AGUDA
}

DOENCA DE C CHAGAS NO RIO G.SUL

EPIDEMIOLOGIA

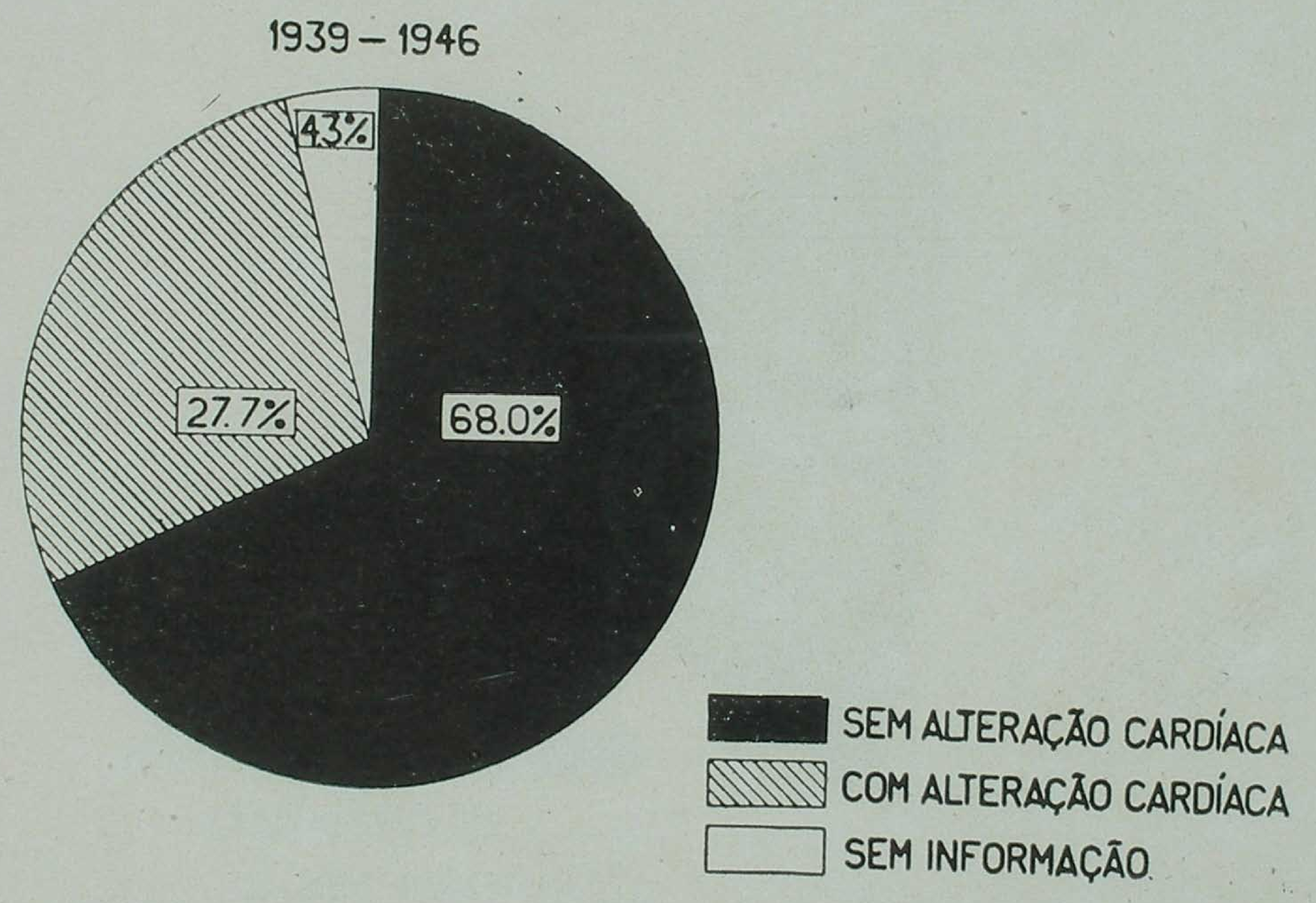




\section{DIAGNÓSTICO PARASITOLÓGICO}

DOENÇA DE C CHAGAS NO RIO G.SUL EPIDEMIOLOGIA

$1939-1946$

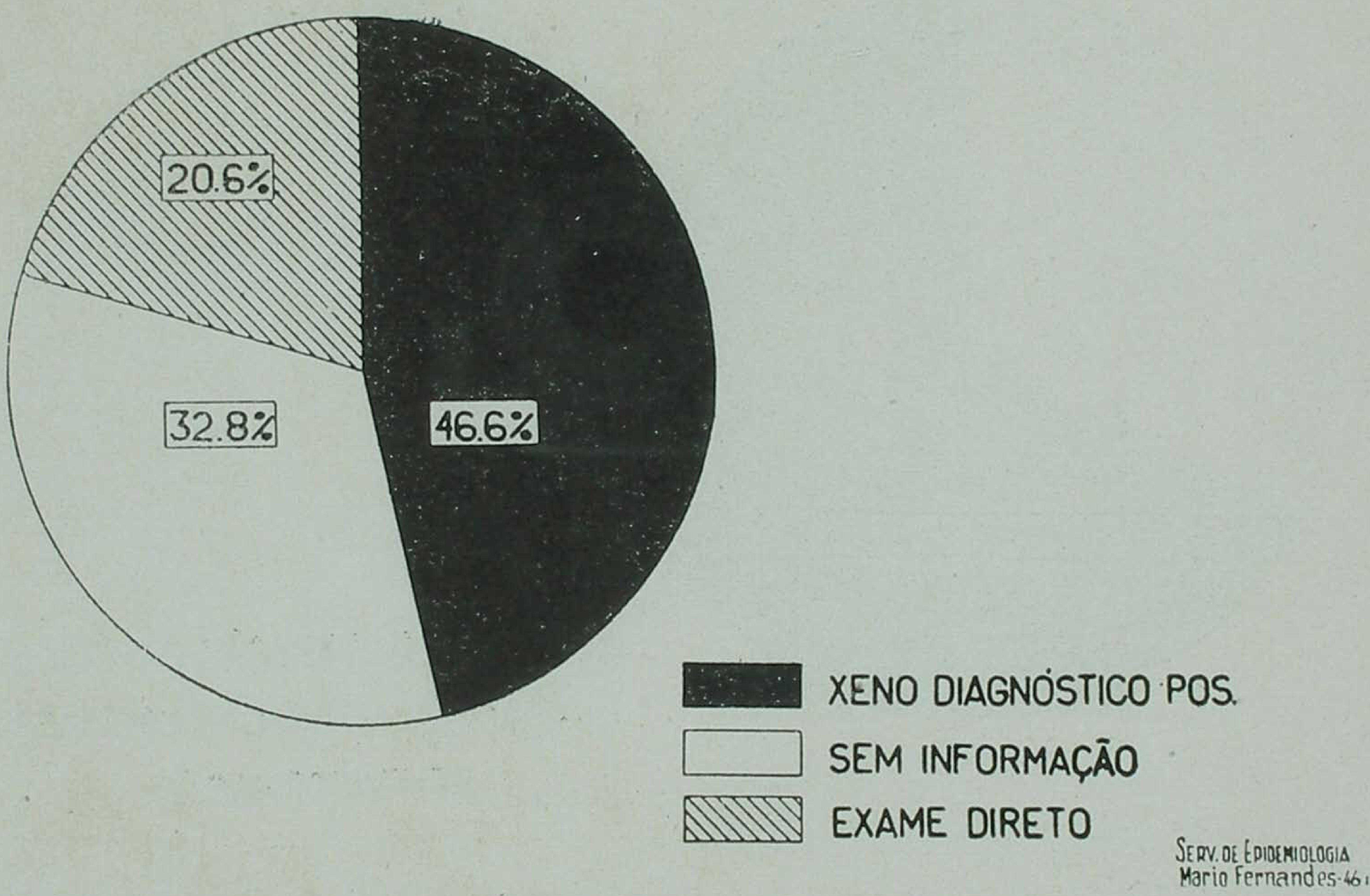

Fig. 25 